\title{
The Market for High-Quality Medicine: Retail Chain Entry and Drug Quality in India
}

\author{
Daniel Bennett \\ University of Chicago
}

\author{
Wesley Yin \\ UCLA
}

November 17, 2014

\begin{abstract}
This study examines the effect of chain store entry on drug quality and prices in the retail pharmacy market in Hyderabad, India. In contrast to prevailing mom-and-pop pharmacies, chains exploit scale economies to offer high-quality drugs at lower cost. With a unique data set and a natural experiment methodology, we show that chain entry leads to a relative 5 percent improvement in drug quality and a 2 percent decrease in prices at incumbent retailers. These changes do not depend on the socioeconomic status of consumers, suggesting that chain entry improves consumer welfare throughout the market. Despite the likely role of asymmetric information in this market, we show that consumers partially infer these quality improvements. Our findings suggest that in markets with asymmetric information, organizational technologies such as chains can play an important role translating greater demand into higher quality.
\end{abstract}

Bennett: dmbennett@uchicago.edu; Yin: wyin@ucla.edu. We benefited from helpful comments from Kerwin Charles, Leemore Dafny, Jeffrey Grogger, Seema Jayachandran, Jens Ludwig, Dilip Mookherjee, Andy Newman, Chad Syverson, Glen Weyl, and seminar participants at Boston University, BREAD, the Indian Institute of Management Bangalore, the University of California Berkeley, the University of Chicago, the University of Maryland, Northwestern University, the Tinbergen Institute, and Yale University. We thank Pallavi Vyas for excellent research assistance. We gratefully acknowledge the financial support of the Bill and Melinda Gates Foundation, the Center for Health Market Innovations at the Results for Development Institute, the Population Research Center and the Center for Health and the Social Sciences at the University of Chicago, and the Institute for Economic Development at Boston University. 


\section{Introduction}

Substandard medicine is a serious public health concern in many developing countries (Bate and Boateng 2007, Gaurdiano et al. 2007). Counterfeiters produce and sell fake drugs that appear legitimate (Dondorp et al. 2004). In addition, so-called local manufacturers produce small drug batches with little regulatory oversight (Corporate Catalyst India 2012). The public health impact of substandard medicine is potentially severe, since these drugs deny patients effective therapies, expose people to toxic impurities, and contribute to pathogenic resistance (Cockburn et al. 2005). Access to effective medicine also has important effects on human capital accumulation, labor supply, earnings, and other economic outcomes (Miguel and Kremer 2004, Baird et al. 2012).

Although economic growth in developing countries has increased consumer wealth and the demand for medicine, it is unclear how income growth leads to higher quality medicine. Wealthier consumers may demand better drugs if quality is a normal good. With larger markets, firms can also exploit economies of scale by making fixed investments that enhance quality (Berry and Waldfogel 2010). ${ }^{1}$ Growth may allow countries to strengthen legal institutions and enforce tort laws, which can foster higher product quality (Spence 1977, Landes and Posner 1987). On the other hand, increases in demand may enhance the market power of firms in markets with capacity constraints (Tirole 1988, Section 5.3), encouraging firms to raise prices or reduce quality. Asymmetric information about drug quality may disincentivize investments in quality, and can even reinforce the incentive for suppliers with market power to reduce quality as demand rises (Dranove and Satterthwaite 1992). Asymmetric information may be particularly severe in pharmaceutical markets since therapeutic effectiveness is hard to for consumers to observe. Because of these considerations, it is unclear whether economic growth leads to higher quality.

Retail chains may play an important role translating economic growth into higher quality

\footnotetext{
${ }^{1}$ Manufacturers can improve quality by strengthening quality control protocols. Distributors and retailers can develop distribution channels that prevent entry by counterfeiters and protect drugs from quality degradation due to extreme heat and humidity.
} 
medicine. Recent economic growth has spurred the entry of pharmacy chains in India, where small mom-and-pop stores have traditionally dominated pharmacy markets. Unlike incumbents, chains are able to exploit scale economies by investing in cost-saving and qualityenhancing technologies. By creating their own supply chains, chains can buy directly from manufacturers while standardizing quality control in distribution. Chains can also exploit scale economies in advertising to signal quality to consumers and overcome information asymmetries (Milgrom and Roberts 1986, Jin and Leslie 2009). These attributes may allow chains to offer high quality medicine despite weak regulation and asymmetric information about drug quality. Although chains may offer higher-quality drugs, the market-wide impact of chain entry depends on the response of incumbent mom-and-pop pharmacies. Chain entry may improve quality among incumbents through retail competition or other mechanisms. Alternatively it may encourage vertical differentiation in which incumbents specialize in cheap, low-quality drugs (Shaked and Sutton 1982), potentially lowering average quality or increasing health disparities.

This study explores the relationship between market development and drug quality by evaluating the impact of chain entry. In 2010, we collaborated with a chain pharmacy, MedPlus, to study the firm's expansion in Hyderabad, India. The chain identified 18 markets it wished to enter. We gathered baseline data in 18 candidate entry markets, as well as two other markets, for a total of 20 markets. Retail space subsequently opened in seven of the candidate markets. The arbitrary availability of suitable space within the firm's expansion time frame, discussed below, creates a naturally experiment that allows us to compare entry (treatment) and non-entry (control) markets and estimate the impacts of chain entry on incumbent drug quality and prices. We resurveyed in all of these markets one year after the firm opened the new stores. Our data feature a "mystery shopper" audit of pharmacies, in which auditors purchased two antibiotics, ciprofloxacin and amoxicillin, under realistic conditions. We chose these drugs because of their wide use and their public health importance for the treatment of bacterial respiratory and gastrointestinal infections. We then assessed 
the quality of the drug samples in a laboratory. We interviewed over 5200 consumers in sample markets, distinguishing between people who had and had not just shopped at sample pharmacies. We also interviewed pharmacists and enumerated the customer traffic at each pharmacy.

We implement a difference-in-differences identification strategy, which relies on the assumption that treatment and control markets have similar counterfactual trends in quality, prices, and firm performance. Several pieces of evidence support this assumption.

- The availability of retail space drove the choice of entry locations. The firm had very specific space requirements and a short window for final expansion in Hyderabad. Because the commercial real estate market is decentralized and thin, the firm only identified seven suitable locations. Afterward, the chain stopped growing in Hyderabad and focused on expansion elsewhere. These conditions create quasi-random variation in chain entry across otherwise similar candidate markets.

- At the beginning of the study, the chain had already opened over 250 stores in virtually all of the more affluent neighborhoods in Hyderabad. The candidate entry markets represented the final phase of entry in the few middle-class neighborhoods it had yet to enter. Neighborhoods that were slightly less affluent were not considered. Therefore, the candidate markets are more homogeneous than the city as a whole. This feature limits the potential for unobservable socioeconomic heterogeneity to confound our estimates.

- Mean baseline prices, quality, customer traffic, and consumer socioeconomic characteristics are statistically similar in entry and non-entry markets. Moreover, the distributions of these drug sample, pharmacy traffic and consumer socioeconomic variables also tightly overlap across treatment and control markets and are not significantly different in Kolmogorov-Smirnov tests. These results suggest that key baseline characteristics did not drive the entry decision and support the claim that the selection of 
entry markets was arbitrary.

- Entry is uncorrelated with trends in consumer demand. A key concern is that, despite assurances that the availability of space dictated entry, executives may have chosen to enter based on private forecasts of consumer demand. Alternatively, the forecasts of other participants in the real estate market might have influenced the availability of space. Using data from one-year and two-year follow-up surveys, we find no statistically significant differences in any measured exogenous socioeconomic trends by treatment status through two years after entry.

- Consistent with this fact, we find that our main treatment effects are large relative to the effects of socioeconomic trends. According to our estimates, market-wide income would need to more than double, and education would need to increase by over five years (nearly 50 percent), in treatment markets to generate the quality and price changes we observe. In reality, we do not observe significant absolute or differential changes in income or education by treatment status during the study period. Any unobservable socioeconomic selection is unlikely to have a stronger effect than these observable SES dimensions.

- More explicitly, we follow Oster (2014) and Altonji et al. (2005) and compute the extent of unobservable selection that would be needed to cause our findings spuriously under the assumption of proportional selection on observables and unobservables. Unobservable selection would need to be remarkably strong to generate our findings.

These patterns support the claim that control markets are a plausible counterfactual for treatment markets.

We find that incumbents improve quality and lower prices once the chain enters. Compliance with the Indian Pharmacopeia quality standard improves by 5 percent and prices fall by 2 percent in treatment markets relative to control markets. Among non-national drug brands, over which pharmacies have more price and quality flexibility, pharmacopeia 
compliance rises by 21 percent and prices fall by 12 percent. We assess the market-wide impact of chain entry by incorporating observations from the chain and interacting chain entry with consumer socioeconomic status. We find no effect for this interaction, implying that chain entry improves consumer welfare regardless of socioeconomic status.

Our results appear to arise primarily through retail competition, rather than other channels. By reducing local monopoly power, the presence of the chain increases the quality elasticity of demand faced by firms, inducing incumbents to improve quality. In principle, the chain, which buys directly from manufacturers, could affect prices or the product mix in the wholesale market. However the wholesale market spans the entire city, and it is unlikely that chain entry in seven locations would have a large aggregate impact through supply-chain externalities. $^{2}$ Chain entry also appears to increase the share of consumers who report that quality is an important attribute, which could also encourage higher quality. The demand increase from this channel alone should increase prices. Our finding that prices decline suggests that competition is an important factor.

The retail competition channel requires that consumers at least partially infer the quality adjustments of firms. We directly analyze these perceptions by regressing perceived quality on chain entry. Although quality is only imperfectly observable, customers appear to infer the incumbent quality changes associated with chain entry to some extent. ${ }^{3}$

Our findings are related to Basker and Noel (2009), Basker (2005) and Jia (2008), who show that chain competition has a large effect on prices in the US, and Domberger and Sherr (1989), Mazzeo (2003), and Matsa (2011) who shows effects of chain entry on quality. We extend this work by studying a context where information asymmetries may contribute to poor quality. By exploiting economies of scale, the chain improves quality and lowers

\footnotetext{
${ }^{2} \mathrm{~A}$ sufficiently large chain expansion could make it more difficult for low-quality manufacturers and wholesalers to exploit scale economies. While this intriguing mechanism may also play a role in quality improvements as markets develop over longer periods, it is beyond the scope of our study.

${ }^{3}$ We investigate whether incumbents invest in costly quality signals (Milgrom and Roberts 1986). We find some evidence of increased air conditioning and store advertising among incumbents in treatment markets, however these effects are imprecise. Incumbents do not need to improve the precision of their signals in order to rationalize these results.
} 
prices, both directly and through competition. Incumbents in entry markets are able to achieve the same quality as the chain but at significantly higher prices, which may reflect the lower productivity of incumbent firms. Our findings are also related to Bate et al. (2011) and Bjorkman-Nyqvist et al. (2012) who show that information asymmetries contribute to poor drug quality in developing countries. Bjorkman-Nyqvist et al. (2012) find that an NGO offering subsidized authentic drugs can reduce incumbent sales of counterfeits. Our study builds upon this work by utilizing natural variation due to the expansion of a chain to measure the impact of competition on quality. We show that markets can overcome asymmetric information to improve quality in the absence of strong regulation and external subsidies by adopting more productive organizational technologies.

We proceed in Section 2 to provide a theoretical motivation for our empirical approach and findings. Section 3 describes the context and the data collection. Section 4 explains and justifies our empirical strategy. In Section 5 we present and interpret our empirical results. Section 6 concludes by discussing the policy implications of our findings. An appendix describes several other robustness tests and secondary results.

\section{Theoretical Motivation}

Our analysis focuses on small independent pharmacies, which compete in local neighborhood markets. Firms compete through price, drug quality, convenience, and other amenities. Pharmacies have some market power because they are differentiated spatially. Consumers must search to gather price and quality information from other pharmacies (Salop 1977, Salop and Stiglitz 1977). We consider the impact of entry by a chain in this setting. ${ }^{4}$ Chains may exploit their scale to invest in cost-reducing and quality-enhancing technologies. For present purposes, we assume simply that the chain is able to produce quality at lower cost than incumbents. In principle, chain and non-chain entry have similar competitive effects. The

\footnotetext{
${ }^{4}$ Economic development may encourage the entry of chains by creating enough demand so that firms can exploit economies of scale. By comparing treatment and control markets with similar trends, our empirical strategy treats this process as exogenous.
} 
key distinction between these firms is that chains are more productive, and so have greater ability to lower costs and raise quality.

In general, the effect of competition on product quality is theoretically ambiguous. Firms with market power may exploit their position to lower quality, just as they may raise prices, and earn positive long-run profits. In the canonical model, competition attenuates market power, causing firms to increase quality, decrease prices, or both. This decision depends loosely on the relative magnitudes of the price elasticity and the quality elasticity of demand (Dorfman and Steiner 1954). Firms are likely to compete through quality if quality improvements translate directly into greater demand. In a setting with fixed prices (e.g. through regulation), the price elasticity of demand is zero and competition unambiguously improves quality (Dranove and Satterthwaite 2000). Bennett et al. (2015) show this effect empirically for antibiotic prescriptions in Taiwan, while Bennett et al. (2013) show it for vehicle emissions inspections in New York State. Competition from a high-quality entrant may also reduce incumbent quality if firms respond by differentiating vertically. In the classic model with heterogeneous consumers, firms locate along a quality continuum and serve customers who prefer quality in the nearby range (Hotelling 1929, Shaked and Sutton 1982). Chain entry increases competition in the high-quality market segment, creating an incentive for incumbents to reduce quality and avoid direct competition. If consumers have heterogeneous quality preferences, competition may also affect quality by changing the identity of the marginal consumer (Spence 1975). In Spence's framework, the firm's marginal revenue from quality is a function of the marginal consumer's willingness to pay for quality. A quantity expansion (e.g. through competition) changes the identity of the marginal consumer, which alters firms equilibrium choices of quality. The sign of this response is ambiguous, and depends upon the specification of preference heterogeneity.

Asymmetric information about product quality may also affect quality provision. In practice, quality is rarely perfectly observable or unobservable; instead consumers receive noisy but informative quality signals. Consumers may need to search for quality information 
(Salop and Stiglitz 1977) or may learn about quality by consuming so-called experience goods (Nelson 1970). People also receive quality signals from advertisements (Nelson 1974), public announcements, and conversations with peers (Allen 1984). Regardless of the learning mechanism, these models converge to the completely unobservable case as the quality signal becomes noisy.

The effect of competition on quality depends on how well consumers perceive quality. Within a search model, Dranove and Satterthwaite (1992) find that the incentive for firms to offer high quality strengthens as the quality signal becomes precise. With a weak quality signal, the effective quality elasticity of demand is low, and firms have weak incentives to improve quality in response to competition. An effect of competition on quality implies that consumers receive quality signals that are at least somewhat informative.

In addition to increasing retail competition, chain entry may affect incumbent quality by reducing the wholesale demand for high-quality medicine. The chain bypasses the wholesale market and purchases directly from manufacturers. This shock may reduce wholesale prices, both overall and particularly for high-quality drugs, which could enable incumbents to improve quality. Finally, chain entry may affect incumbent quality by changing consumer demand. The chain might inform consumers about the distribution of drug quality or alter their preferences for high-quality medicine. Either mechanism shifts out the retail demand for medicine, which should increase the price. The chain may also alter the selection of customers who shop at incumbent pharmacies, which is a possibility we discuss further in the appendix.

\section{Empirical Context, Data and Chain Entry}

\subsection{Context}

India's pharmaceutical sector produces 13 percent of global pharmaceutical output (CCI 2012). The industry consists of around 250 large "national manufacturers" and around 8000 
small "local manufacturers." Many national manufacturers work to comply with both domestic and international quality standards. India has 74 FDA-approved manufacturing plants, more than any country besides the United States. National manufacturers advertise heavily to establish brand reputation and enhance market power. In contrast, local manufacturers produce and disseminate small batches of common generic medicines, at times incentivizing local doctors and pharmacies to push their products. Regulators struggle to provide effective oversight for the large number of local manufacturers. To accommodate demand for a wide variety of local brands, retailers commonly stock dozens of brands of popular generic compounds (Kamat and Nichter 1998).

Several factors contribute to heterogeneous drug quality in India. To achieve consistent high quality, manufacturers must invest heavily in quality control equipment and protocols (Woodcock 2004, Yu 2008). Quality control investment is more challenging than procuring pharmaceutical components, which are cheap and available. With summertime temperatures that exceed 40 degrees Celsius, distributors and retailers must safeguard inventory from heat and humidity. Corrupt wholesalers may mix counterfeit and authentic drugs. Counterfeits imitate the appearance of well-known brands but are not intended to be therapeutic. Because pharmaceutical components are inexpensive, counterfeiters may evade detection by including active ingredients in their products (Newton et al. 2008). ${ }^{5}$

Consumers have difficulty observing drug quality. During the sale, a consumer sees the brand, the condition of the packaging, and the manufacture and expiry dates. The consumer's change in health after taking the medicine provides another noisy signal. ${ }^{6}$ While they may not know the quality of specific units of inventory, pharmacists are relatively informed about average quality because they maintain longstanding distributor relationships. A pharmacist can improve drug quality by purchasing different inventory, changing distrib-

\footnotetext{
${ }^{5} \mathrm{An}$ extensive literature in public health shows that counterfeits are pervasive in developing countries (Cockburn et al. 2005, Dondorp et al. 2004, Sow et al. 2002, Taylor et al. 2001).

${ }^{6}$ Without observing a counterfactual, the consumer cannot isolate the drug's contribution to her change in health. The consumer's health may improve through a placebo effect or may fail to improve because the drug is not the correct therapy.
} 
utors, or improving storage conditions, all of which may raise costs.

Our audit focuses on ciprofloxacin and amoxicillin, two broad-spectrum antibiotics that are widely used to treat ear, urinary tract, respiratory, and digestive tract infections. Both drugs are sold in blister pack "strips" of 8-10 tablets. Patients often use these drugs incorrectly to treat viral infections. Consumers have difficulty gauging effectiveness because they often do not know whether an illness is bacterial. Ciprofloxacin and amoxicillin are suited to a mystery shopper audit because pharmacies stock many brands of these drugs and sell them frequently.

An examination of the quality-price gradient allows us to gauge the information asymmetry in this market. In a hedonic framework, the price reflects the marginal consumer's valuation of the product. Consumers should be unwilling to pay a premium for quality that they cannot observe. In an approach similar to Bate et al. (2011), Figure 1 shows the kernel density of price for high-quality and low-quality drugs in our data (described below). High-quality medicine is more expensive on average, which suggests that consumers receive some quality information. The heavy overlap in these distributions indicates that other factors influence price. In particular, the price distributions are bimodal because of the different pricing strategies of premium and discount brands. A density plot for residual prices (conditional on the manufacturer and other observable product features) shows even greater overlap between high-quality and low-quality drugs. Figure 2 directly considers the availability of information through a scatterplot of actual and perceived market-wide quality. The gradient in this figure is positive and significant but the $R^{2}$ of the regression is 0.08 , which suggests that consumers perceive quality in a noisy fashion.

The Drugs Control Administration (DCA) is the main pharmaceutical regulator in India. The agency oversees both manufacturers and retailers. The DCA has a reputation as an ineffective regulator because it has repeatedly failed to detect substandard medicine (Kashmir Times 2009). In one instance, the DCA conducted pharmacy audits but did not test the audit samples for 14 months, by which time many samples had expired (Mahesh 2010). The 
DCA seems to provide more thorough oversight of national manufacturers than local manufacturers. Despite these shortcomings, the agency appears to limit the flagrant counterfeiting that is reported in settings with even weaker governance (e.g. Gaurdiano et al. 2007).

Hyderabad, the fourth largest city in India and the capital of Andhra Pradesh. Small, independent "mom-and-pop" pharmacies predominate in Hyderabad and elsewhere in India. These firms offer most common drugs and rarely require a prescription. Shops are typically small, unenclosed storefronts without air conditioning. In our data, pharmacies occupy a median of 350 square feet of retail space. Pharmacies usually employ workers without formal training.

Pharmacy markets are hyperlocal, with customers shopping a median of 0.5 kilometers from their homes in our data. Markets in our study contain a median of 24 pharmacies per square kilometer. Pharmacies advertise through prominent storefront signage. Each manufacturer determines a "maximum retail price", which appears on the packaging. The wholesale price is tied to the MRP, which restricts the retailer's ability to offer a discount without losing money. However the MRP varies widely across brands (a 10-tablet strip in our data ranges from US\$0.46 to $\$ 2.00$ ), so pharmacists can lower the price by substituting a cheaper brand.

Conventionally pharmacies obtain inventory from a multilayered wholesale market. Retail pharmacies buy from wholesalers, who buy from regional "super-stockists", who buy from "carry and forward" agents, who in turn buy from manufacturers. Pharmacies in our sample purchase from a median of eight wholesalers. With many agents in the supply chain, careless or corrupt wholesalers can undermine quality with impunity. The complexity of the supply chain also inflates wholesale and therefore retail prices. Hyderabad does not have a centralized wholesale marketplace. Instead wholesalers deliver inventory directly to shops. 


\subsection{MedPlus Organization and Expansion}

Chain pharmacies have expanded rapidly through Indian cities in recent years. Chains cater to relatively affluent customers by offering amenities such as air conditioning and more knowledgeable staff. With over 250 local stores, MedPlus is the largest of three chains operating in Hyderabad during the study period. MedPlus was established in 2008 and grew rapidly in Hyderabad, Chennai, Bangalore, and elsewhere in southern India. The firm

markets itself as an inexpensive, high-quality provider. It obtains discounts on inventory by purchasing in bulk directly from manufacturers and in turn offers consumers a 10 percent discount from the MRP of national-brand drugs. MedPlus also contracts with a handful of manufacturers to offer "own-brand" alternatives to the non-national brands found at incumbent pharmacies. Direct purchasing allows MedPlus to offer high-quality medicine by avoiding the quality issues associated with the wholesale market.

\subsection{Data}

This study relies on an original data set that measures the quality, price, and performance of retail pharmacies. We surveyed in 20 markets (described below) from May-July of 2010 ("Round 1"), one year later ("Round 2") and in a more limited fashion two years later ("Round 3"). The chain entered seven of the candidate markets between Rounds 1 and 2 . In the Empirical Strategy section below, we validate the assumption that entry into candidate markets was plausibly exogenous.

We began by conducting a census of pharmacies within 0.5 kilometers of the center of each market. Within each market, we enrolled the three nearest incumbent pharmacies to where the chain wished to enter, plus two others at random, for a total of 100 incumbent pharmacies. For each sample pharmacy, we conducted mystery shopper audits, drug quality testing, a pharmacy survey and a customer traffic enumeration. We also surveyed local consumers about recent drug purchases, drug quality perceptions, demographics, and health. In Round 3, we repeated all surveys except for the audit and pharmacy surveys. Drug quality 
and price data are therefore available in Rounds 1 and 2, but not Round 3. In Rounds 2 and 3, we also included the newly-opened chain pharmacies in the sample.

We audited each pharmacy four times per round in order to stratify by drug and auditor SES. ${ }^{7}$ Auditors were careful to interact naturally with pharmacists. The auditor requested the compound (ciprofloxacin or amoxicillin) but allowed the pharmacist to choose the brand. This approach gave the pharmacist latitude to substitute between brands with different quality levels and profit margins. The laboratory required three strips (30 tablets) to conduct quality tests, so auditors revisited pharmacies and bought two more strips of the same brand several days later. Audit visits comprise a tiny fraction of total customer traffic over the sample period.

A laboratory in Delhi tested the drugs samples for compliance with Indian Pharmacopeia, the official drug quality standard in India. A sample of ciprofloxacin or amoxicillin complies with Indian Pharmacopeia standards by falling within the official thresholds for active ingredient concentration, dissolution, and uniformity of weight. We conducted tests for all three dimensions of quality. The active ingredient concentration of the samples must be within 90-110 percent of the labeled dosage. Dissolution indicates the percent of the sample's active content that dissolves into a known medium within a predetermined time, and must exceed 80 percent for the sample to comply. To measure uniformity of weight, the analyst weighs 30 individual tablets. The uniformity parameter is a function of both the minimum and the maximum absolute deviation in weight within the sample, and must be less than 5 for amoxicillin and less than 7.5 for ciprofloxacin. ${ }^{8}$ Figure 3 shows the sample distributions of these quality components. Drusano (2004) describes how these quality dimensions map into patient health. Patients respond to antibiotics in heterogenous ways. Small quality

\footnotetext{
${ }^{7}$ We validated the distinction between high-SES and low-SES mystery shoppers by asking consumer survey respondents to identify the SES of auditors from photographs. Respondents nearly always answered correctly.

${ }^{8}$ The measurement error for each continuous quality test depends on the number tablets in the sample. Our mystery shopper audit includes 30 tablets, which leads to measurement error of 1-2 percent in each continuous quality outcome, according to the laboratory. The error rate for pharmacopeia compliance is even lower because most samples are not on the margin of compliance. Laboratory-based quality measurement is more informative than Raman spectroscopy, which only indicates whether a sample is authentic.
} 
deficiencies may have important health impacts for patients who already respond poorly to antibiotic treatment.

Overall, over 96 percent of the audit samples comply with Indian Pharmacopeia. Among non-national drugs, only 93 percent comply with the quality standard. This rate is similar for both antibiotics, and is in line with the reported national compliance rate of 91 percent in 2003 (Sheth et al. 2007). Among substandard samples, 69 percent fail the active ingredient requirement, 22 percent fail the uniformity requirement, and 58 percent fail the dissolution requirement. Figure 3 plots the densities of these components. Quality is optimized at the intended active ingredient dosage, and increases monotonically in dissolution and decreases in uniformity of weight. The positive and negative dispersion in active ingredient concentration around 100 percent reinforces that quality control is an important quality determinant. Limited data indicate that pharmacopeia compliance is much higher in developed countries (Trefi et al. 2007). ${ }^{9}$

Our analysis distinguishes between drugs from national and non-national manufacturers. Retailers have relatively limited discretion over the quality and price of national brands. Customers are less willing to substitute away from brands with reputations for high quality. Consequently, many national-brand manufacturers exercise market power and set wholesale prices so that retailers have slim margins. In contrast, quality is more heterogeneous among local brands, and retailers have more discretion over pricing and brand selection. A research assistant collaborated with laboratory officials to categorize each manufacturer as national, local, or other, based on information from manufacturer websites and direct knowledge of large firms. In our analysis, we combine "local" and "other" categories. Since pharmacists select the brand in our audit, the sample's status as national or non-national is endogenous. However a regression of national status on chain entry shows no effect $(\hat{\beta}=0.004, \hat{\sigma}=$

\footnotetext{
${ }^{9}$ Trefi and coauthors find that ciprofloxacin samples from Germany and New Zealand contain 99.3-99.7 percent of the correct active ingredient dosage $(n=8)$. Bate et al. (2012) audit the authenticity of online drug purchases shipped to the United States. With the exception of Viagra purchased from uncertified pharmacies, they find no counterfeit samples.
} 
$0.08, p=0.96){ }^{10}$

Our consumer survey is a repeated cross-section that measures demographic characteristics, drug purchases, drug quality perceptions, and health. We enrolled half of the sample from among people who had just visited sample pharmacies $(n=2602)$ and half from among other adults who were present in the area $(n=2632)$. This approach allows us to measure the characteristics of both actual and potential pharmacy shoppers. To enumerate customer traffic, surveyors counted the number of customers entering each pharmacy from 6-7PM and from 7:30-8:30PM on randomly chosen days. We selected these windows because in pilot data the bulk of customer traffic occurs in the evening.

\subsection{Chain Entry}

In the spring of 2010, MedPlus executives assisted us by identifying 18 candidate markets it wished to enter. With over 250 stores throughout the city, MedPlus had already entered all of the most affluent markets and nearly exhausted its expansion opportunities. This step was the final phase of expansion in Hyderabad. After the 2010 expansion, the firm shifted its focus toward growth in other cities. Between Rounds 1 and 2, MedPlus entered 7 of the 18 candidate entry markets. We surveyed in all 18 markets with the expectation that suitable retail space would not become available in every candidate market, and that non-entry markets could serve as controls in this study. ${ }^{11}$

Our budget allowed us to survey two additional markets, which we selected for their similarity to the 18 candidate markets and the absence of chain pharmacies. Compared to the 18 candidate markets, the two additional markets have lower socioeconomic status, with 23 percent lower household income and 1.7 fewer years of schooling $(p<0.01$ for both

\footnotetext{
${ }^{10}$ National brands have both higher prices and quality than non-national brands. If competition has both price and quality effects (as we suggest below), then the impact on the composition of national and non-national brands is ambiguous because the price and quality effects work in opposite directions.

${ }^{11}$ In markets that the firm entered, the prospective and actual entry locations are very similar. As with other experimental and quasi-experimental designs, our estimates are local to the markets in the study. The impact of chain entry in more or less affluent markets is uncertain. Consumer SES may affect both the baseline level of quality and the optimal response to chain entry.
} 
variables). We include these markets to improve precision: standard errors are around 15 percent larger if we exclude these markets. However, Appendix Table 2 shows that price and quality results are slightly larger and remain significant if we leave these markets out. Figure 4 shows the locations all 20 markets within Hyderabad. ${ }^{12}$

Table 1 compares the chain stores to incumbents in Round 2. We prefer to draw a comparison to incumbents in control markets, since chain entry may have influenced the characteristics of treatment incumbents. The table shows that prices are 6 percent lower $(p=0.02)$ and pharmacopeia compliance is 6 percentage points higher $(p=0.46)$ at the chain. All MedPlus stores are air conditioned, compared to just 12 percent of incumbents.

\section{Empirical Strategy}

\subsection{Empirical Approach}

In this section, we estimate the effect of chain entry on incumbent drug quality and prices using a difference-in-difference approach. In the following specification, $s$ indexes the audit scenario, $i$ indexes the pharmacy, $m$ indexes the market, and $t$ indexes the time period:

$$
y_{\text {simt }}=\beta_{1} \text { Post }_{t}+\beta_{2} \text { Post }_{t} \cdot \text { Entry }_{m}+\Omega_{m t}^{\prime} \beta_{3}+\alpha_{m}+\varepsilon_{\text {simt }}
$$

Post $_{t}$ is an indicator for Round 2 and Entry $m$ is an indicator for entry markets. Market fixed effects, $\alpha_{m}$, control for baseline market heterogeneity. Some regressions include market demographic and health controls, $\Omega_{m t} \cdot{ }^{13}$ We cluster standard errors by market, which may lead us to underestimate the standard errors with only twenty markets (Donald and Lang 2007).

\footnotetext{
${ }^{12}$ Entry markets are an average of 3.4 kilometers farther from the city center than control markets. Because the metropolitan area has grown through the convergence of the twin cities of Hyderabad and Secunderabad, the "center" of Hyderabad is not necessarily a meaningful reference point. In the appendix, we use multiple approaches to show that unobservables correlated with the distance to the city center do not confound our results.

${ }^{13}$ Regressions that use pharmacy fixed effects yield very similar estimates. Demographic controls include education, income, household size, caste, and vehicle ownership. Health controls include the prevalence of diarrhea, fever, cough and cold, and injuries. We use the non-shopper sample to calculate market · time averages for all variables.
} 
Therefore we also report the p-value for each coefficient of interest using Cameron, Gelbach and Miller's (2008) wild cluster bootstrap. We report specifications with and without controls for some specifications as a way of gauging the potential selection bias in our estimates. For these regressions, we also report Oster (2014) $\delta$ values, which indicate the extent of proportional unobservable selection that would be necessary in order for $\beta_{1}=0$. We discuss this test further in Section 5.2 below.

\subsection{Identification}

For our approach to identify treatment effects, unobserved time-varying determinants of quality and other outcomes must be uncorrelated with chain entry. Differential trends in the supply and demand of high-quality medicine in treatment and control markets could violate this assumption. This subsection discusses contextual and statistical reasons why this assumption is reasonable in this application.

\subsubsection{Contextual Evidence}

According to chain executives, the availability of suitable retail space was the sole determinant of entry among the candidate entry markets. They did not base this decision on any other factors, such as inside knowledge of market growth or price and quality trends. The chain had specific space requirements of 1000-1200 square feet on the ground level facing a busy commercial street within the specified neighborhoods. Commercial real estate markets in Hyderabad are decentralized. Individual brokers maintain proprietary listings that are difficult to search, and are based in part on previous client interactions (Das et al. 2013). Although the market is active, the chain was not always able to find available retail real estate that met its size, configuration and location requirements for one of its stores. Entry occurred only when retail space meeting relatively narrow requirements became available. The adherence to retail space requirements over the short time frame of the chain's final phase of expansion in Hyderabad contributes to plausibly exogenous variation in the availability 
of suitable space across treatment and control markets.

Also, the nature of the chain's expansion strategy limits the potential for selection on time-varying unobservables. According to chain executives, the affluence of the neighborhood is the main characteristic that they use to identify candidate entry markets. When we began the study, the firm had already opened 250 stores in all of the more affluent neighborhoods in the city. Moreover, the chain did not consider entry in any neighborhood that was less affluent than the candidate markets. ${ }^{14}$ The candidate entry markets in our study are more homogeneous than the city as a whole. The limited amount of variation means that any unobservable selection is unlikely have a large impact on our estimates.

\subsubsection{Statistical Evidence}

Chain entry appears to be uncorrelated with unobservable quality and price determinants. Table 2 compares the baseline characteristics of pharmacies, drug samples and consumers in treatment and control markets. In Panel A, audit samples from treatment and control markets have nearly identical prices and quality. The price per tablet differs by US $\$ 0.001$ $(p=0.75)$ and the rate of Indian Pharmacopeia compliance differs by $0.005(p=0.92)$. Samples have similar values for active ingredient concentration and dissolution. Uniformity is somewhat higher in entry markets but does not account for any Indian Pharmacopeia failures in Round 1. In Panel B, treatment and control pharmacies are comparable in terms of air conditioning, cleanliness, and customer traffic. These patterns suggest that supply-side factors such as market concentration are not correlated with treatment status.

Panel C assesses whether baseline consumer characteristics are correlated with treatment. The panel focuses on the non-shopper sample to avoid selection, although statistics for shoppers are similar. Log income, educational attainment, household size, and vehicle ownership are comparable for treatment and control consumers. Treatment consumers are more likely to belong to a scheduled caste or tribe. The baseline similarity of these de-

\footnotetext{
${ }^{14}$ For example, survey data confirms that the two additional markets we surveyed have incomes that are slightly lower than the 18 candidate markets. Yet the chain opted to pass on these two markets.
} 
mographic characteristics suggests that chain entry is not related to the level of customer demand.

A comparison of means may mask heterogeneity in the distributions of these characteristics. Such heterogeneity may be important if the demand for medicine responds in a non-linear way to socioeconomic status. For example, holding the mean constant, an increase in the variance in income may increase drug demand if high-income people disproportionately buy medicine. Figure 5 shows the distributions of drug sample, pharmacy, and consumer socioeconomic variables by treatment status. These distributions tightly overlap. In Kolmogorov-Smirnov tests, uniformity is the only variable out of nine for which the treatment and control distributions are significantly different with $p \leq 0.10$.

Next we examine whether treatment and control markets exhibit differential changes in socioeconomic characteristics, which may shift the demand for medicine. We may spuriously attribute the effect of a demand shock to chain entry if the chain selectively enters markets with rising demand for high-quality medicine. Table 3 reports the difference-in-differences for these variables. We do not find significant differences by treatment status in socioeconomic trends between Rounds 1 and 2. Moreover, trends in these variables continue to be similar across treatment and control markets through Round 3, nearly two years after entry into the treatment markets. ${ }^{15}$ The absence of differential trends in these variables supports the claim that entry is uncorrelated with determinants of demand. Appendix Table 3 also finds no correlation between chain entry and the composition of customers at incumbent pharmacies.

The statistical evidence strongly supports the similarities across treatment and control markets along observed baseline and time-varying characteristics. To investigate the extent of selection along unobserved time-varying factors, we conduct two robustness tests in Section 5.2. Using the coefficients on market-wide income and education, we compute the extent of

\footnotetext{
${ }^{15}$ We have not identified administrative data that would allow us to test for differential pre-trends. In principle, we could use the Indian census to calculate 10-year demographic changes from 2001 to 2011, which would encompass Rounds 1 and 2 of our survey. We have not pursued this approach because census geographic units align poorly with the markets in our data set and because 10-year differences do not seem informative for identification.
} 
selection on these variables that would be needed to generate our findings. The variation that would be needed is an order of magnitude larger than the actual variation in the data. Secondly, we follow Oster (2014) and Altonji et al. (2005) and compute the extent of unobservable selection that would be needed to generate our findings spuriously under the assumption that observable and unobservable selection are proportional. These results suggest that unobservable selection would need to be very strong to generate our findings spuriously, a finding we discuss at greater length in Section 5.2.

Finally, patterns in the pharmacy census do not suggest that chain entry is associated with other market trends. Chain entry is not correlated with the closure of incumbent pharmacies, which could otherwise suggest a shift in demand toward high-quality medicine. This fact is not surprising since the chain and incumbents operate in distinct segments of the commercial real estate market. If unobservable trends make treatment markets more profitable than control markets, we might expect greater non-chain entry in treatment markets. However non-chain entry is similar across treatment and control markets, with an average of 1.14 entrants in treatment markets and 1.15 entrants in control markets between Rounds 1 and 2 .

\subsection{Trends by Treatment Status}

Our estimates are identified through the differential change in price and quality in entry markets relative to control markets. Figure 6 shows this variation by plotting the trends in price and pharmacopeia compliance. After adjusting for inflation, the price of audited drugs in control markets is constant over time while the price declines by around 2 percent in entry markets.

The figure shows that quality falls by 5 percentage points in control markets but remains constant in entry markets. Marked climate changes from Round 1 to Round 2 most likely explain this secular quality decline. Humidity and temperature are the most important environmental determinants of quality for antibiotics (Peace et al. 2012), which is why MedPlus 
air conditions all of its stores. According to weather data from NOAA, peak relative humidity during the data collection was 8.7 points higher $(p=0.04)$ for Round 2 than for Round 1. ${ }^{16}$ The combination of high heat and humidity is particularly harmful to drugs (Kiron et al. 2011, Mubengayi et al. 2013). Following these pharmacology studies, we use a maximum temperature thresholds for safe drug storage of 30 degrees Celsius and a relative humidity threshold of 60 percent, and find that the share of audit days with poor conditions rose from 54 percent in Round 1 to 97 percent in Round $2(p<0.001) .{ }^{17}$

\section{Results}

\subsection{The Impact of Chain Entry}

Chain entry has a dramatic effect on incumbents. Table 4 shows the effect of chain entry on log customer traffic and market exit. The table shows that shows that customer traffic increased by 25 percent over two years for control incumbents but stagnates for treatment incumbents. 96 percent of control incumbents who were present in Round 1 remain in Round 3, compared to 91 percent of treatment incumbents. Both of these results are statistically significant. ${ }^{18}$ For regressions with controls, the table (as well as Tables 5 and 7 ) reports the proportional selection $\delta$ based on Oster (2014). We discuss and interpret these statistics in

\footnotetext{
${ }^{16}$ Weather readings are from the Hyderabad International Airport. We obtain similar results if we include the two weeks prior to the audit, when some drugs may have been in inventory.

${ }^{17}$ The combination of demand growth and incumbent capacity constraints may also contribute to this pattern. The limited availability of retail space creates a capacity constraint for firms, which may create market power by allowing firms to avoid price competition (Kreps and Scheinkman 1983). Increases in demand accentuate market power as long as capacity lags behind demand. Chain competition in treatment markets counteracts this incentive by reducing excess demand. Table 4 shows that customer traffic grew rapidly for control incumbents but did not change for treatment incumbents. Across markets, the correlation between the changes in customer traffic and pharmacopeia compliance is -0.16 , which indicates that quality worsened in markets where demand rose. Customer waiting times, which are available through the mystery shopper audit, proxy for the presence of capacity constraints. We find that the quality change is small and insignificant for the first three quartiles, ranked by wait times. For pharmacies with the longest waiting times, quality falls by 11 percentage points.

${ }^{18}$ The pharmacy census, which is the source for market exit results, encompasses all firms in the 20 sample markets. Results for quality, price, and customer traffic are based on a sample of 100 pharmacies. Only one of these pharmacies exits from Round 1 to Round 2, so our data do not indicate whether firms with high-quality or low-quality medicine differentially exit.
} 
Section 5.2 below.

Regression estimates for drug quality appear in Table 5. Columns 1 and 2 use the full sample of drug manufacturers. Column 1, which is the regression analog of the quality graph in Figure 6, shows that chain entry increases pharmacopeia compliance by 4.3 percentage points. ${ }^{19}$ This effect rises to 6.6 percentage points after controlling for demographic and health characteristics in Column 2. The rest of the table distinguishes between drugs from national and non-national manufacturers. In Columns 3 and 4 , we find no effect of chain entry on the quality of national brands. In contrast, Columns 5-7 show a large and significant effect on the quality of non-national brands: pharmacopeia compliance rises by 20-24 percentage points relative to control markets. Effects are significant using either marketclustered standard errors or Cameron et al.'s (2008) wild cluster bootstrapped standard errors.

Pharmacies may change quality by substituting within or across manufacturers. Quality factors related to distribution and storage, such as counterfeits and climate control, contribute to within-manufacturer quality heterogeneity. Columns 6 and 7 quantify this decomposition by excluding and including manufacturer fixed effects. Controlling for manufacturer fixed effects in Column 7 attenuates the treatment effect estimate by 38 percent, which suggests that substitution within manufacturers is responsible for 62 percent of the treatment effect for non-national drugs.

We analyze the impact of chain entry further by examining the impact the components of drug quality. Figures 7 and 8 show the change over time in the distributions of both active ingredient concentration and dissolution in treatment and control markets. A similar graph for uniformity (for which we find no effect) is available from the authors. In Figure 7, quality worsens in control markets because mass shifts from the 95-100 percent range to the 85-90 percent range. The distribution shifts leftward, particularly at the low end of the distribution, where there is an increase in the mass below 90 percent, the minimum for

\footnotetext{
${ }^{19}$ This estimate is based on a change from 8 to 10 total failures in treatment markets and a change from 16 to 41 total failures in control markets.
} 
pharmacopeia compliance. In the lower panel, quality improves in entry markets because mass shifts from the 105-115 range to the 95-100 percent range, which reduces high-end failures. In Figure 8, the modal value for dissolution shifts to the right in both treatment and control markets. However, mass in the left tail (which is the source of pharmacopeia failures due to insufficient active ingredient) is eliminated in treatment markets but expands in control markets. ${ }^{20}$ We analyze these effects further in the appendix.

As we describe in Section 3.3, a sample complies with Indian Pharmacopeia by achieving predetermined thresholds for active ingredient concentration, dissolution, and uniformity of weight. Table 6 shows the impact of chain entry on these components for the full sample (Panel A) and the sample from non-national manufacturers (Panel B). Columns 1-3 report results for active ingredient concentration. ${ }^{21}$ The quantity of active ingredient declines by $6.86 \mathrm{mg}$ in control markets and by $3.33 \mathrm{mg}$ in treatment markets, leading to a (statistically insignificant) treatment effect estimate of $3.53 \mathrm{mg}$ in Column $1 .^{22}$ Because quality is nonmonotone for active ingredient concentration, and is optimized at the labeled dosage, Column 2 reports the effect on the absolute percent deviation from the labeled dosage. This estimate is pronounced and statistically significant for non-national drugs. Column 3 shows that chain entry increases the probability of compliance with the active ingredient requirement by 4.2 percentage points overall and by 18 percentage points for non-national drugs.

The rest of the table shows the impact on dissolution and uniformity of weight. Columns 4 and 5 report the effects of chain entry on dissolution. Dissolution improves in treatment markets while it remains constant or declines slightly in control markets, leading to a significant effect on this dimension of pharmacopeia compliance. We find no effect of chain entry on uniformity of weight. Low values indicate greater uniformity, which equates to higher

\footnotetext{
${ }^{20}$ All of these shifts are statistically significant. Kolmogorov-Smirnov p-values are 0.002 and 0.034 in the upper and lower panels of Figure 7 and are less than 0.001 for both panels of Figure 8 .

${ }^{21}$ Figure 3 shows the frequency distributions for these quality components, pooling samples of ciprofloxacin and amoxicillin from all sample manufacturers.

${ }^{22}$ Column 1 excludes seven observations with a labeled dosage of $250 \mathrm{mg}$. Pharmacists provided these samples as substitutes for the $500 \mathrm{mg}$ samples the auditors requested. Normalizing the dosage to 100 percent and including these observations does not affect the estimate.
} 
quality. Columns 6 and 7 show that average uniformity rises between the survey rounds, but pharmacopeia compliance is unchanged in both treatment and control markets. ${ }^{23}$

Table 7 shows the impact of chain entry on log price. As above, we examine the full sample and then distinguish between national and non-national drugs. Columns 1 and 2 show an insignificant 2-4 percent effect on price in the full sample. The effect on price for national drugs is also insignificant in Columns 3 and 4 . However chain entry leads to a significant 12-15 percent price decline for non-national drugs. Columns 6 and 7 decompose this effect into inter-manufacturer and intra-manufacturer components. The coefficient is the same in both specifications, which suggests that firms reduce prices by offering discounts rather than substituting toward cheaper brands.

\subsection{Robustness}

The coefficient estimates for income and education in Tables 5 and 7 allow us to gauge the likelihood that selection on time-varying unobservables confounds our estimates for drug quality and prices. The effect of income on drug quality is 0.0000028 in the regression in Column 2 of Table 5 (result not reported). To improve quality by 4.3 percentage points, as we observe, income would need to increase differentially by $\$ 349$ per month in real terms in treatment markets, which is more than double the baseline monthly income of $\$ 249$ and is an order of magnitude larger than the actual change in income over the study period. Similarly, the coefficient on education is 0.0082 , meaning that average education would need to increase differentially by 5.3 years in treatment markets to generate the quality result, a nearly 50 percent increase in educational attainment. In reality, average education does not exhibit a significant differential trend and, if anything, appears to decline slightly over time in Table 3. We repeat this exercise for the price regressions. Here, too, coefficient estimates for income and education suggest that unrealistic increases in income and education would be

\footnotetext{
${ }^{23} \mathrm{~A}$ plot of the uniformity distribution before and after entry (available from the authors) resolves this apparent discrepancy by showing that the uniformity distribution shifts leftward and also incorporates a larger right tail.
} 
needed to generate the observed results. These effect sizes make it unlikely that time-varying unobservables cause our results spuriously.

Next we follow Oster (2014), Altonji et al. (2005) and Krauth (2011), who compare treatment effects with and without controls in order to gauge the role of unobservable selection. Some specifications control for contemporaneous market demographic and health characteristics and other specifications control for the interaction of these baseline characteristics and Post. If unobservables that are positively correlated with these controls influence chain entry, then including the controls should attenuate our estimates. The usefulness of this exercise depends on the explanatory power of the controls (Oster 2014). Oster derives bounds on the treatment effect under an assumption of proportional selection, which generalizes the approaches of Altonji et al. (2005) and Krauth (2011).

We report the "proportional selection $\delta$ " for specifications below with controls. The $\delta$ in Osters model measures the strength of unobservable selection relative to observable selection. A value of $\delta=1$ indicates that there is equal selection on observables and unobservables. We report the value of $\delta$ that is necessary to negate the observed treatment effect. A large value of $\delta$ means that unobservable selection would need to be exceptional strong to explain the treatment effect. ${ }^{24}$ In many cases, such as the main price and quality regressions, including controls increases the treatment effect estimates slightly. $\delta$ is negative in these cases, which implies that negative selection on unobservables would be needed to eliminate the effect. Since most plausible sources of bias are positively correlated with the controls, negative values of $\delta$ support the robustness of our estimates.

Table 8 explores the robustness of our results by controlling for the interaction of Post and three sets of baseline observable characteristics, including market demographic characteristics, market health characteristics, and pharmacy characteristics. We describe the demographic and health variables above. Pharmacy characteristics include customer traffic,

\footnotetext{
${ }^{24}$ This exercise also requires us to specify the maximum share of the variation in the dependent variable that could arise through selection. We obtain this parameter by regressing each dependent variable on market - time fixed effects. Our rationale is that these effects capture all market-wide information that the chain could have used as the basis for entry decisions.
} 
establishment age, signage, and space allocated to medicine. In Columns 1-3, the effect on drug quality remains statistically significant and varies from 0.14 to 0.22 , compared to the the estimate of 0.20 in Table 5. In Columns 5-7, the effect on log price is also significant (except for Column 7) and ranges from -0.10 to -0.20 , compared to -0.11 in Table 7 . The proportional selection $\delta$ is generally either large or negative in all specifications, which indicates that the effect of unobservables confounds must be larger than (or negatively correlated with) the effect of observed variables driving the treatment effect. Only in one specification, in column 2 , is the $\delta$ positive and less than one.

Our results may arise because of regression toward the mean if the chain enters markets where quality is unexpectedly low or price is unexpectedly high. We investigate this possibility by interacting Post $_{t}$ with the baseline value of the dependent variable (averaged by pharmacy) in Columns 4 and 8 of Table 8 . These controls do not affect the magnitude or significance of our estimates. In the appendix, we use a similar approach to show that heterogeneity in the proximity to the city center and growth in customer traffic do not explain our results.

\subsection{Consumer Perceptions}

Next we examine the effect of chain entry on perceived quality. Quality competition is only profitable if consumers perceive quality adjustments and increase demand at firms that improve quality. The consumer survey elicits the respondent's perception of quality on a four-point Likert scale for "nearby pharmacies" and for "national brand" and "local brand" drugs. We limit the sample to non-shopping consumers. Chain entry may have affected the selection of shoppers surveyed, making changes in quality perceptions among shoppers difficult to interpret. Although it is possible that non-shoppers are less informed about drug quality, in practice shoppers and non-shoppers buy medicine with similar frequencies. Estimates for shoppers (available from the authors) closely resemble the estimates for nonshoppers in both magnitude and significance. 
Table 9 reports the effect of chain entry on perceived quality. With three consumer survey rounds, we estimate separate effects for Rounds 2 and 3. Columns 1 and 2 show a positive and significant effect of chain entry on the perceived quality of nearby pharmacies. Standard errors are smaller and effects are more significant in Round 3 because the data from Round 2 have a higher intracluster correlation. Estimates become larger once we include demographic and health controls in Column 2. Columns 3 and 4 show a generally insignificant effect on the perceived quality of national drugs. These findings are consistent with the small actual impact on quality for these drugs; however the large coefficient in Column 4 suggests that consumers sometimes hold inaccurate perceptions. In contrast, Columns 5 and 6 show a large and significant effect for local drugs, which is consistent with actual increases in quality in entry markets over this period..$^{25}$

\subsection{Interpretation}

Retail competition is the most plausible explanation for our results. Chain entry reduces the demand and increases the elasticity of demand for treatment incumbents. These effects are particularly clear for non-national drugs, over which firms have the greatest discretion. These effects appear to arise through chain competition. In addition to seven MedPlus stores, an average of 1.15 non-chain stores enter treatment markets and 1.14 non-chain stores enter control markets from Round 1 to Round 2, an insignificant difference. Estimates (available from the authors) show small and insignificant effects of non-chain entry on quality and price. Moreover, controlling for non-chain entry does not affect our estimates of the impact of chain entry. The chain's impact may be especially large because the chain competes aggressively through price and signals quality more effectively than mom-and-pop firms.

Alternatively, chain entry may affect incumbent quality via the wholesale market. By purchasing directly from manufacturers, the chain reduces the wholesale demand for medicine.

\footnotetext{
${ }^{25}$ Firms may signal higher quality in either observable or unobservable ways. Appendix Table 4 shows mixed and statistically insignificant evidence of pharmacy and drug improvements in terms of several observable dimensions. We discuss quality signaling further in the appendix.
} 
However, our results are unlikely to arise through this channel because the wholesale market spans the city and is geographically diffuse. Any impact on wholesale demand is localized in treatment markets, which are a very small subset of all markets in the city. The seven new chain stores represent less than three percent of MedPlus stores, and less than 0.2 percent of pharmacies in the city

Chain entry may directly increase the demand for high-quality medicine by shifting consumer perceptions or quality preferences. In the consumer survey, respondents indicate whether drug quality, store convenience, and store familiarity are important considerations when purchasing medicine. We restrict the sample to non-shopping consumers; the responses of shoppers are more difficult to interpret because these respondents have elected to purchase medicine. Appendix Table 6 shows that chain entry increases the importance that consumers report placing on drug quality, which suggests that the chain increases the preference for highquality medicine. Chain entry does not increase the perceived importance of other pharmacy characteristics. An increase in demand for high-quality medicine cannot, alone, explain our findings on its own because greater demand should increase prices. The price reductions in Table 7 suggest that competition over price and quality is the dominant channel.

Chain entry may affect incumbent prices or quality by changing the selection of incumbent shoppers. Because the chain offers both higher quality and lower prices, it does not necessarily draw away high-SES or low-SES customers differentially. If it steals high-SES customers, the chain may encourage incumbents to cater to the remaining low-SES customers through lower prices and quality. Because both quality preferences and drug demand are positively correlated with SES, customer selection cannot explain why chain entry has different effects on quality and prices. We investigate the role of selection further by regressing the demographic characteristics of incumbent customers on chain entry in Appendix Table 3. With estimates that are small and statistically insignificant, the table shows no effects of chain entry on shoppers characteristics. These results cast doubt on selection-based explanations for the price and quality effects of chain entry. 


\subsection{The Market-wide and Distributional Impacts}

Although incumbents respond to chain entry by lowering prices and improving quality, they remain at a competitive disadvantage to the chain. In Table 10, we restrict the sample to treatment markets after entry and regress pharmacopeia compliance and log price on an indicator for the chain. Columns 1 and 2 show that while quality is similar, the chain offers 6 percent lower prices than incumbents in entry markets $(p=0.16)$. Columns 3 and 4 focus only on brands that both the chain and incumbents carry. For these brands, drugs from the chain are 5 percentage points more likely to comply with the pharmacopeia standard and are priced 9 percent lower. These patterns suggest that the chain is more productive, and continues to benefit from its distinctive supply chain even after incumbents have responded to entry.

A welfare assessment of chain entry should incorporate both the presence of the chain and the incumbent response. We measure the market-wide impact of chain entry by including observations from the seven new chain outlets in Round 2. We also weight the regressions by customer traffic to account for heterogeneity in pharmacy size. Estimates of the marketwide impact of chain entry appear in Table 11. In Columns 1 and 2, chain entry increases pharmacopeia compliance by 5-7 percent, which is a slightly larger than our previous estimate. In Columns 5 and 6 , chain entry reduces price by 5-6 percent, which is roughly double the impact on prices for incumbents only in Table 7. Including observations from the chain strengthens the price result because the chain consistently underprices incumbents.

We also examine whether the effect of chain entry depends upon the socioeconomic status of consumers. High-SES consumers may better perceive drug quality heterogeneity and more strongly prefer high-quality medicine. Similarly, low-SES consumers may be more price sensitive, leading to greater price competition for these customers. These consumer attributes could influence the optimal incumbent response to chain competition. Firms may cater to consumers of a particular socioeconomic status or may discriminate by treating high-SES and low-SES consumers differently. 
The remainder of Table 11 explores two possible heterogeneous treatment effects by consumer SES. In Columns 3 and 4, we compute the average education of each pharmacy's shoppers and distinguish between pharmacies that are above and below the median. Column 3 shows that quality rises differentially (but insignificantly) for pharmacies that serve highSES customers. With a positive coefficient on Post . Entry $_{m}$, chain entry also improves the quality of low-SES shops. Columns 4 and 8 exploit the audit stratification by mystery shopper SES to investigate possible SES-based discrimination. The regressions show small and insignificant interactions with auditor SES, which suggests that firms do not discriminate across customers within stores. Therefore, both high-SES and low-SES consumers appear to benefit from the competitive effects of chain entry.

\section{Conclusion}

We show that chain entry leads to higher quality and lower prices, both for incumbent pharmacies and for the overall retail market. This impact is the greatest for non-national brands, which have the most baseline quality heterogeneity, and over which pharmacies have the most quality and price discretion. The lack of clear socioeconomic heterogeneity in these effects suggests that chain entry has broad market-wide consumer benefits. The chain's ability to undercut incumbents in terms of price suggests that chains will continue to succeed in Indian pharmacy markets.

Our results are informative about the information asymmetry between pharmacies and consumers, and possible channels through which quality improvements can take place in light of information asymmetries and weak regulatory institutions. Consumers accurately infer quality changes associated with chain entry, which indicates that they do receive informative quality signals. In the appendix, we show mixed evidence of investment in quality signals and discuss how incumbents may communicate quality information to consumers in other ways.

Markets plagued by information asymmetries typically call for regulation. However im- 
plementing strong regulation is not usually feasible in developing countries. This study suggests that in settings with weak regulation, productivity-enhancing technologies such as chains may help overcome information asymmetries. The results also imply that policymakers may be able to encourage drug quality by facilitating pharmacy chains. While dynamic considerations are beyond the scope of this study, we note that by Round 2, incumbents are able to achieve the quality levels attained by the chain, but with higher prices, which suggest higher costs. The productivity differences suggest that chains may replace mom-andpop pharmacies as the dominant organizational model. In the short run, the implications for quality and price as incumbents exit are ambiguous. In the long run, this scenario is likely lead to competition among more productive chains, a pattern seen in more developed countries. 


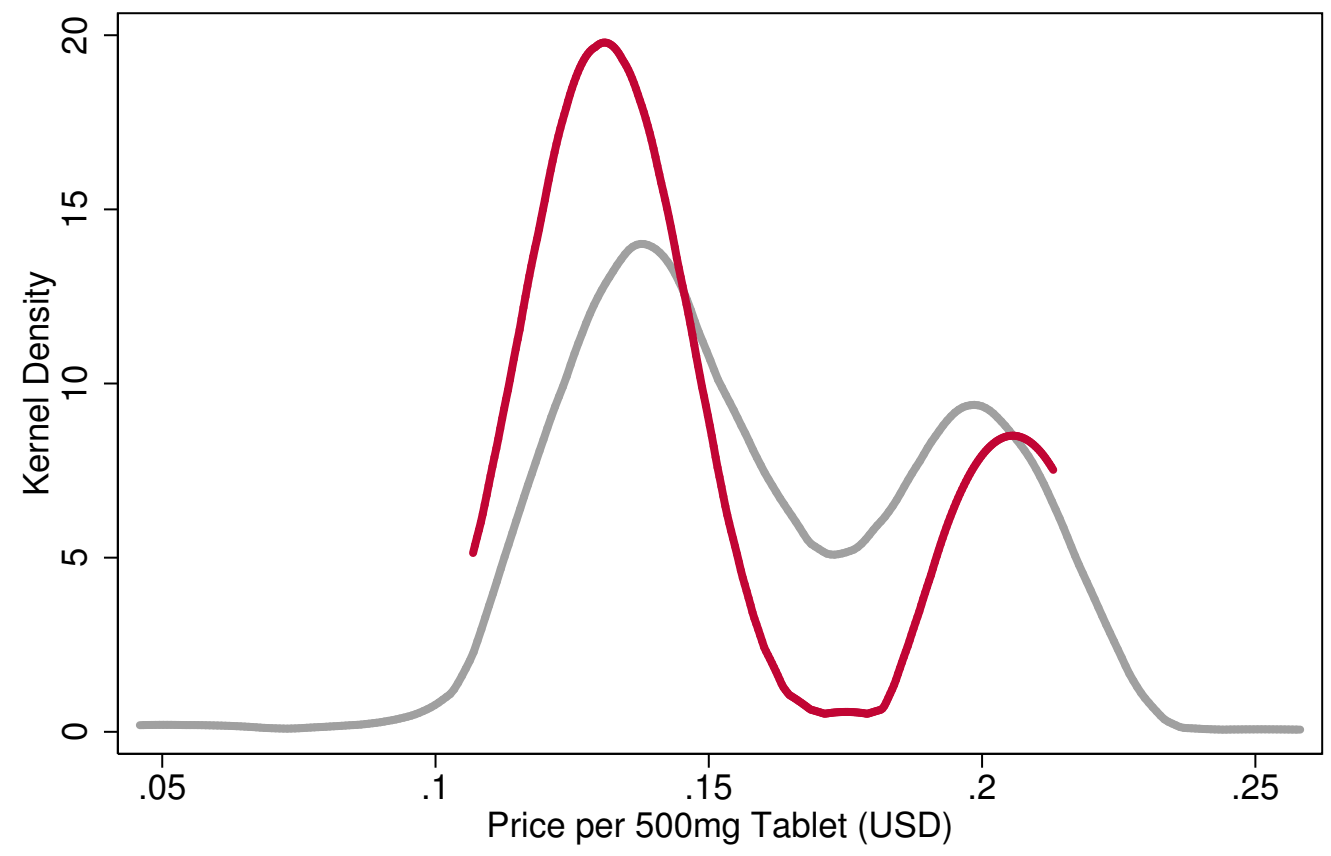

High-Quality Samples $\longrightarrow$ Substandard Samples

Figure 1: The Price Distribution for IP Compliant and Non-Compliant Samples

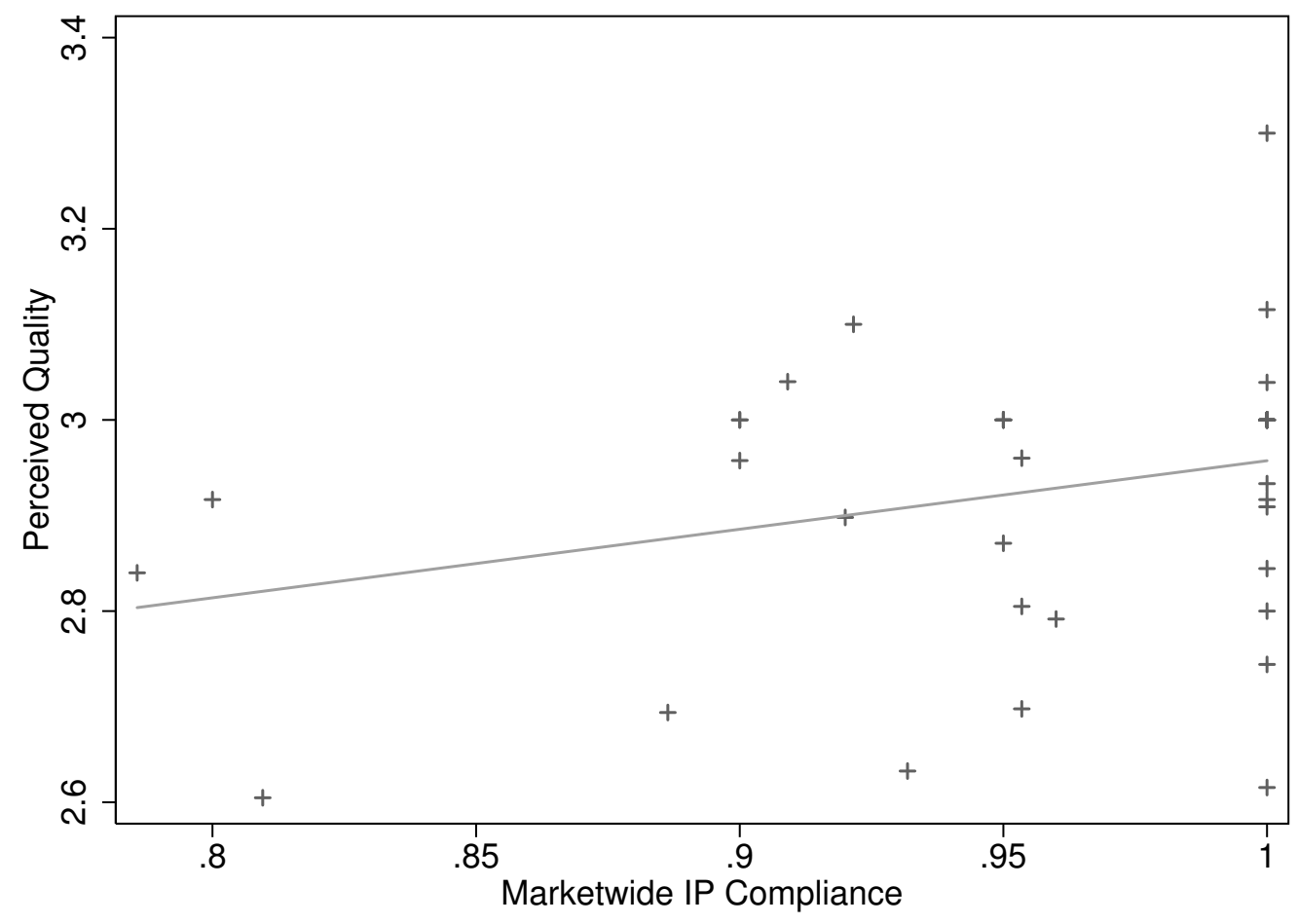

Figure 2: Actual and Perceived Quality by Market 

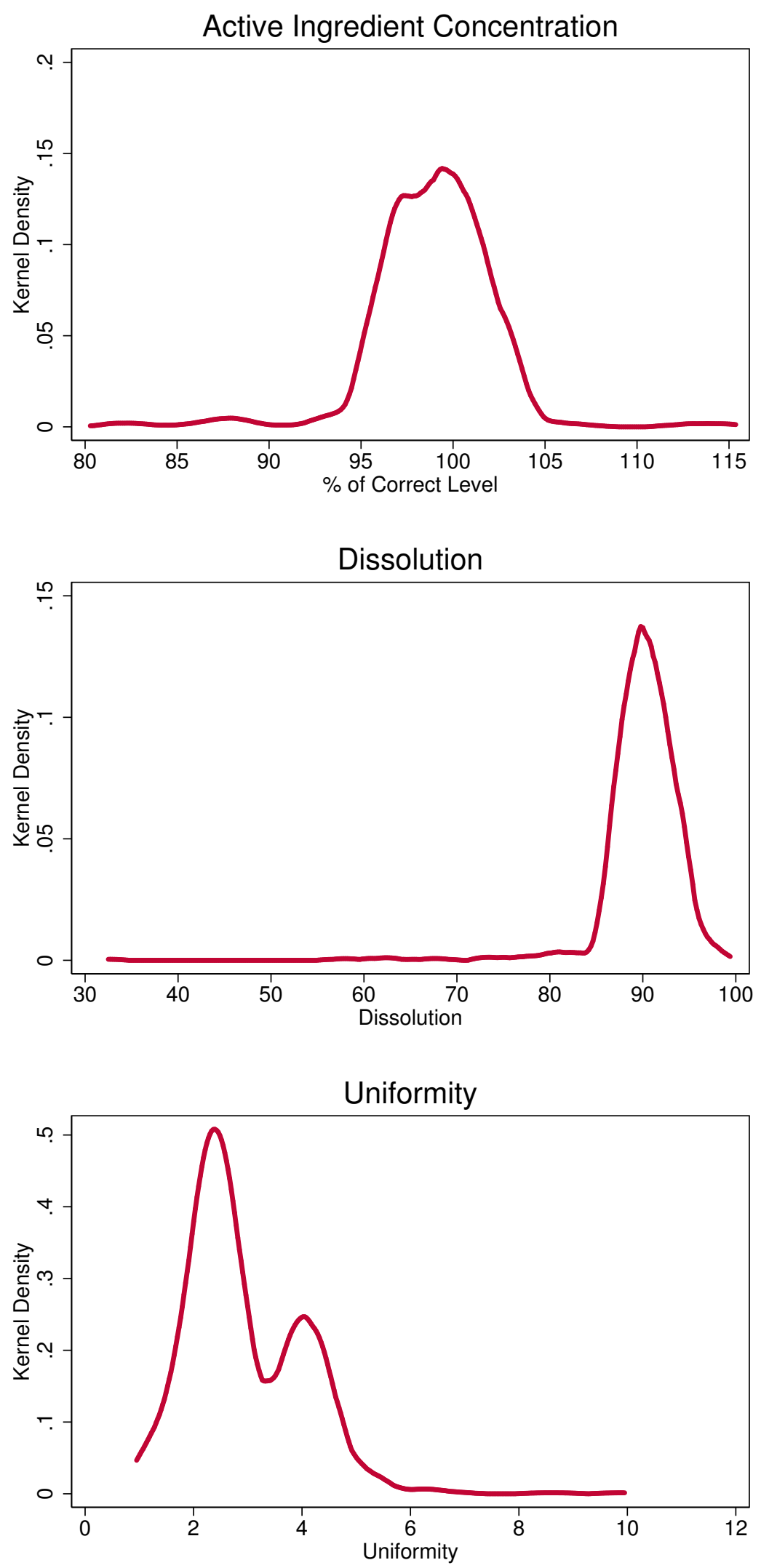

Figure 3: The Distribution of Quality Components 


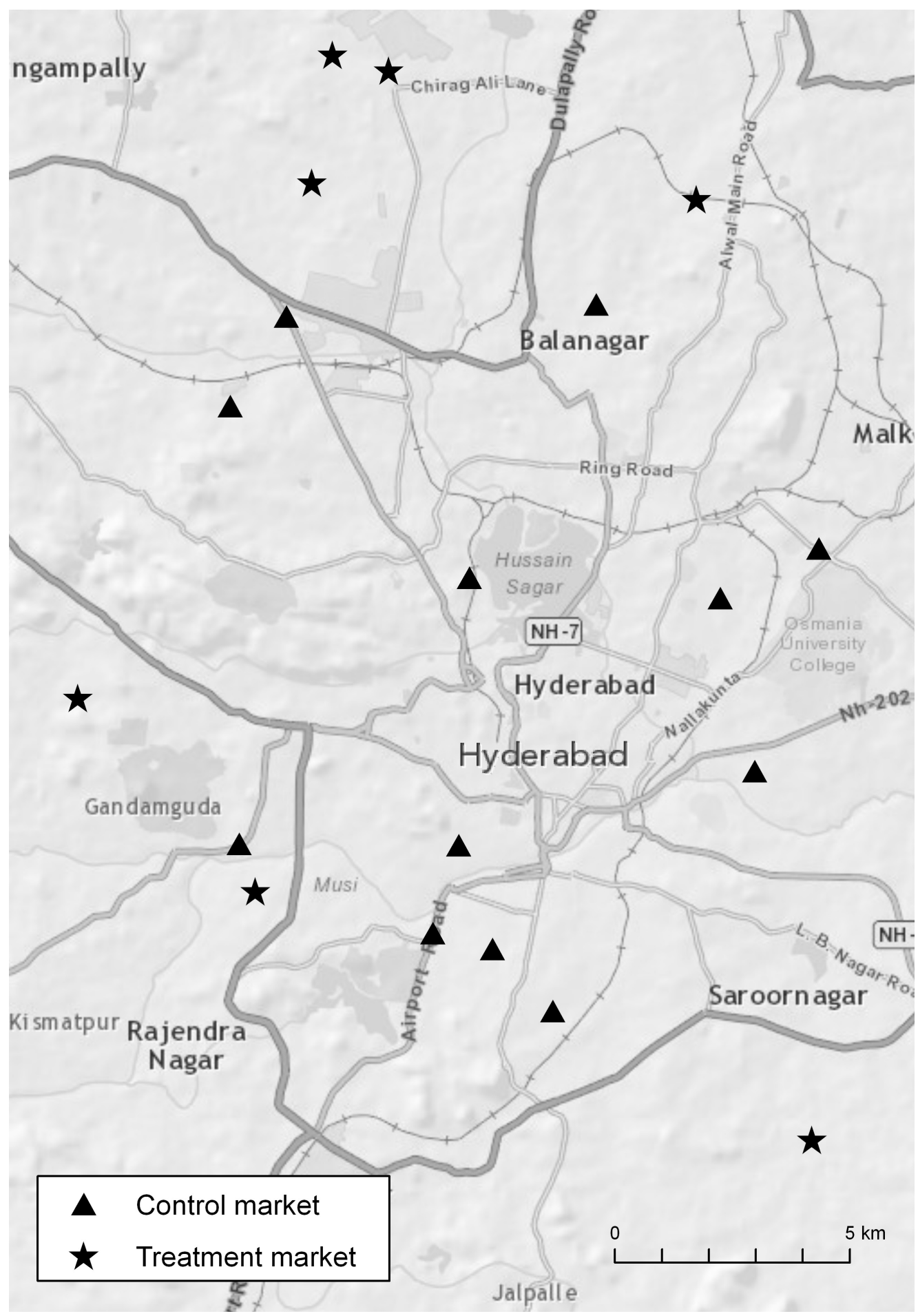

Figure 4: The Location of Sample Markets in Hyderabad 

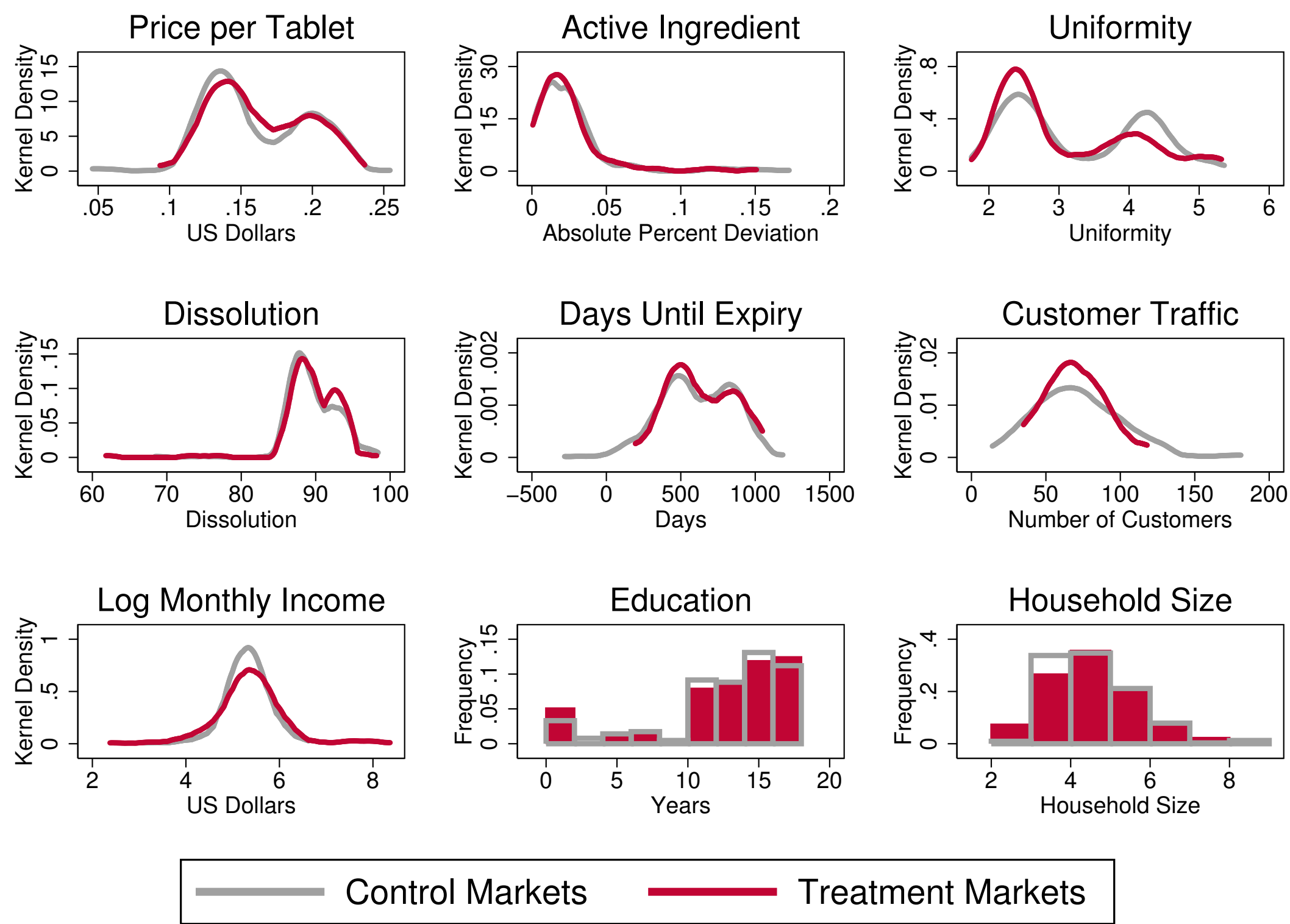

Figure 5: Baseline Distributions of Non-Binary Characteristics in Treatment and Control Markets 

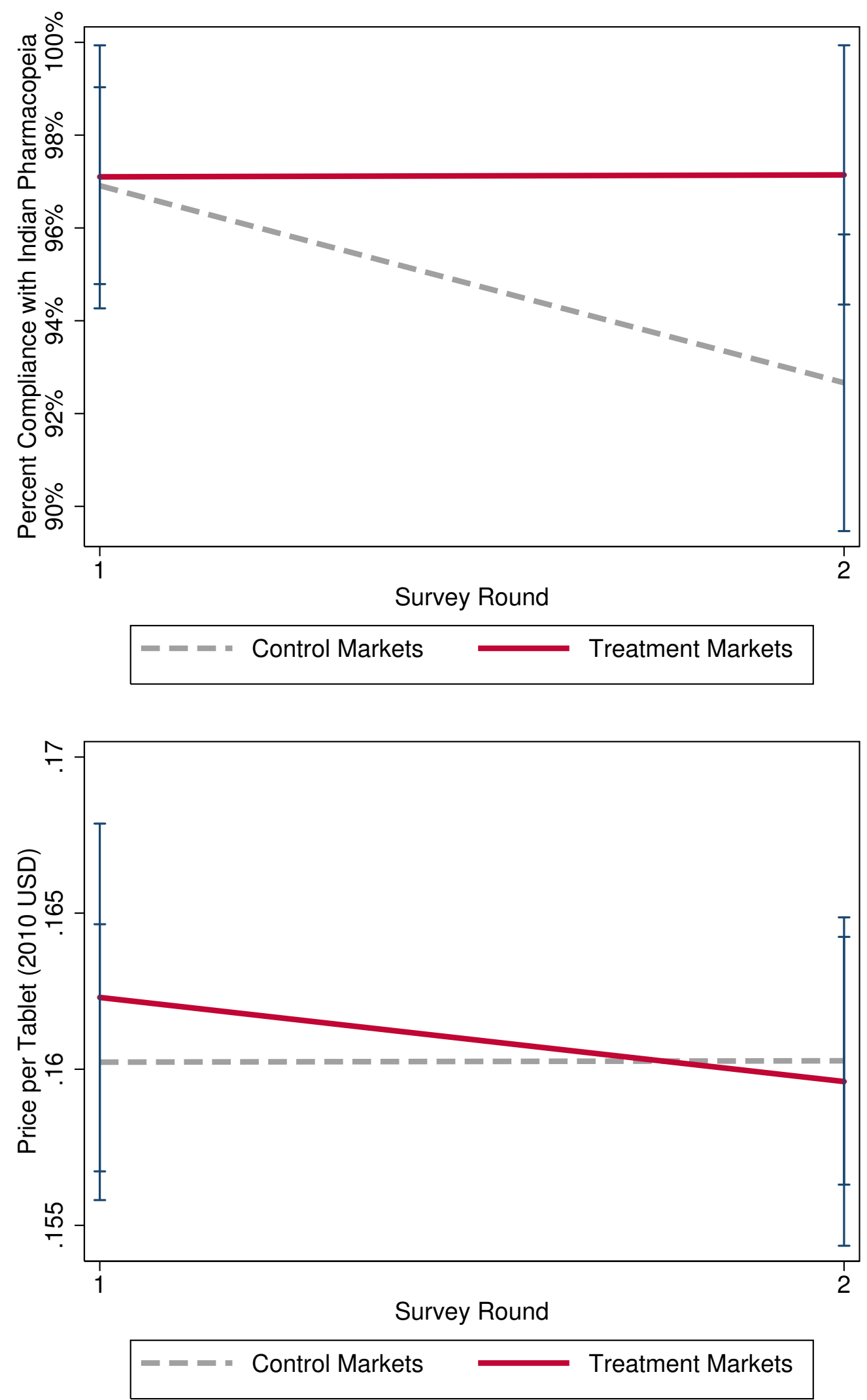

Figure 6: Quality and Price Changes 

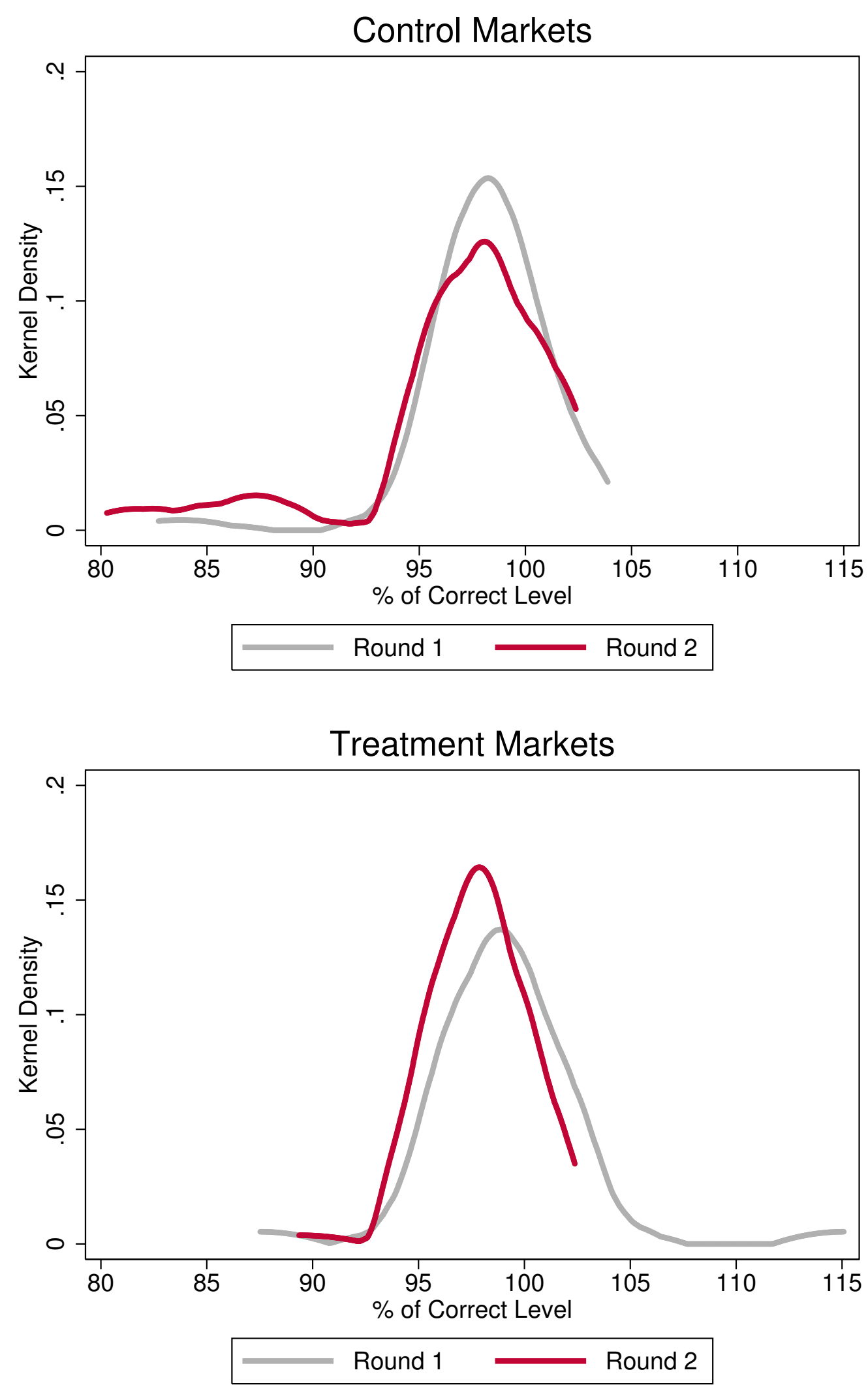

Figure 7: The Density of Active Ingredient Concentration for Non-National Drugs 

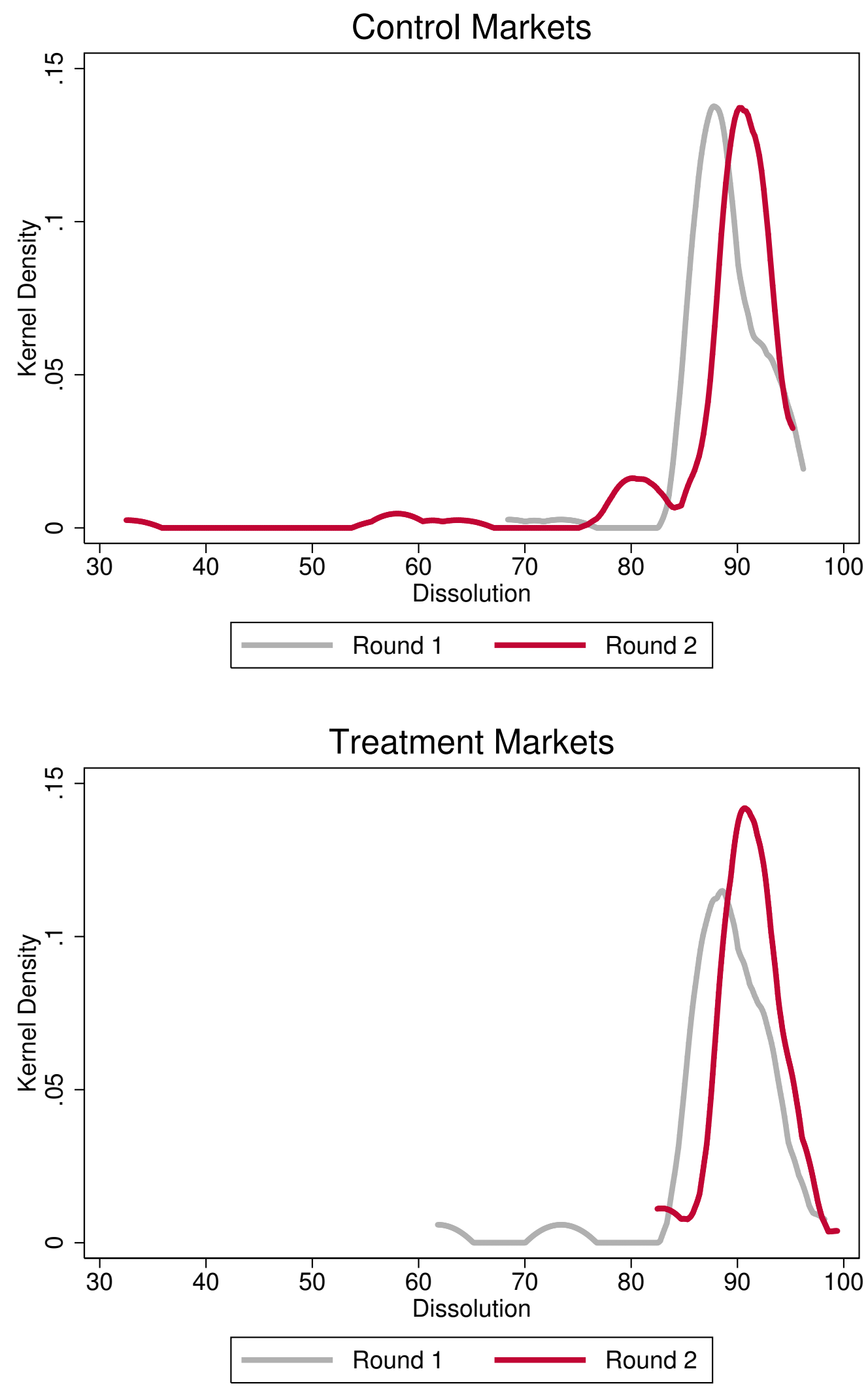

Figure 8: The Density of Dissolution for Non-National Drugs 
Table 1: Characteristics of MedPlus and Control Incumbents After Entry

Control

MedPlus Incumbents

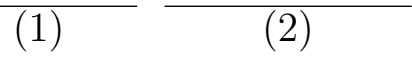

Panel A: Drug and Pharmacy Characteristics

$\begin{array}{lll}\text { Price per 500mg Tablet (USD) } & 0.148 & 0.160^{*}\end{array}$

Complies with Indian Pharmacopeia $\quad 0.964 \quad 0.927$

Air conditioning $\quad 1.00 \quad 0.12^{* * *}$

Cleanliness (1-5) $4.9 \quad 4.0^{* * *}$

Panel B: Shopper Characteristics

\begin{tabular}{lll}
\hline Log Monthly household income (USD) & 5.36 & 5.36
\end{tabular}

$\begin{array}{lll}\text { Education (years) } & 11.7 & 11.8\end{array}$

$\begin{array}{lll}\text { Distance from home } & 1.53 & 1.66\end{array}$

Note: The table reports characteristics in Round $2 .{ }^{*} p<0.1,{ }^{* *} p<0.05,{ }^{* * *} p<0.01$. 
Table 2: Baseline Characteristics of Treatment and Control Markets

\begin{tabular}{|c|c|c|}
\hline & $\begin{array}{c}\begin{array}{c}\text { Control } \\
\text { Markets }\end{array} \\
(1)\end{array}$ & $\begin{array}{c}\begin{array}{c}\text { Treatment } \\
\text { Markets }\end{array} \\
(2)\end{array}$ \\
\hline \multicolumn{3}{|l|}{ Panel A: Drug Sample Characteristics } \\
\hline Price per 500mg Tablet (USD) & 0.161 & 0.163 \\
\hline Complies with Indian Pharmacopeia & 0.969 & 0.971 \\
\hline Active ingredient (deviation from 100\%) & 0.025 & 0.023 \\
\hline Uniformity & 3.27 & $3.09^{*}$ \\
\hline Dissolution & 89.6 & 89.6 \\
\hline Days until expiry & 608 & 640 \\
\hline Sample size & 517 & 276 \\
\hline \multicolumn{3}{|l|}{ Panel B: Pharmacy Characteristics } \\
\hline Air conditioning & 0.16 & 0.09 \\
\hline Cleanliness (1-5) & 4.03 & 3.97 \\
\hline Customer traffic & 71.5 & 69.5 \\
\hline Sample size & 65 & 35 \\
\hline \multicolumn{3}{|l|}{ Panel C: Consumer Characteristics } \\
\hline Log monthly household income (USD) & 5.30 & 5.37 \\
\hline Education (years) & 12.2 & 12.0 \\
\hline Household size & 4.1 & 4.0 \\
\hline Scheduled caste/tribe & 0.06 & $0.17^{* * *}$ \\
\hline Owns a vehicle & 0.64 & 0.57 \\
\hline Sample size & 317 & 177 \\
\hline
\end{tabular}


Table 3: Trends in Socioeconomic Status for Treatment and Control Markets

\begin{tabular}{|c|c|c|c|c|c|c|}
\hline & \multicolumn{3}{|c|}{ Rounds 1 and 2} & \multicolumn{3}{|c|}{ Rounds 1 and 3} \\
\hline & \multicolumn{2}{|c|}{ First Difference } & \multirow{2}{*}{$\frac{\mathrm{DD}}{\frac{(2)-(1)}{(3)}}$} & \multicolumn{2}{|c|}{ First Difference } & \multirow{2}{*}{$\begin{array}{c}\text { DD } \\
\frac{(5)-(4)}{(6)}\end{array}$} \\
\hline & $\frac{\text { Control }}{(1)}$ & $\frac{\text { Treatment }}{(2)}$ & & $\frac{\text { Control }}{(4)}$ & $\frac{\text { Treatment }}{(5)}$ & \\
\hline Log monthly household income (USD) & $\begin{array}{c}0.05 \\
(0.07)\end{array}$ & $\begin{array}{l}-0.03 \\
(0.15)\end{array}$ & $\begin{array}{l}-0.08 \\
(0.15)\end{array}$ & $\begin{array}{l}-0.15 \\
(0.06)\end{array}$ & $\begin{array}{l}-0.02 \\
(0.12)\end{array}$ & $\begin{array}{c}0.13 \\
(0.13)\end{array}$ \\
\hline Education (years) & $\begin{array}{c}0.05 \\
(0.53)\end{array}$ & $\begin{array}{l}-1.19 \\
(0.75)\end{array}$ & $\begin{array}{l}-1.23 \\
(0.88)\end{array}$ & $\begin{array}{l}-2.31 \\
(0.46)\end{array}$ & $\begin{array}{l}-1.32 \\
(0.64)\end{array}$ & $\begin{array}{c}0.98 \\
(0.77)\end{array}$ \\
\hline Household size & $\begin{array}{c}0.18 \\
(0.19)\end{array}$ & $\begin{array}{c}0.18 \\
(0.17)\end{array}$ & $\begin{array}{r}-0.002 \\
(0.24)\end{array}$ & $\begin{array}{c}0.85 \\
(0.16)\end{array}$ & $\begin{array}{c}0.60 \\
(0.14)\end{array}$ & $\begin{array}{l}-0.25 \\
(0.20)\end{array}$ \\
\hline Scheduled caste/tribe & $\begin{array}{c}0.03 \\
(0.03)\end{array}$ & $\begin{array}{l}-0.02 \\
(0.04)\end{array}$ & $\begin{array}{l}-0.05 \\
(0.04)\end{array}$ & $\begin{array}{c}0.12 \\
(0.03)\end{array}$ & $\begin{array}{c}0.02 \\
(0.05)\end{array}$ & $\begin{array}{l}-0.11^{*} \\
(0.07)\end{array}$ \\
\hline Owns a vehicle & $\begin{array}{l}-0.07 \\
(0.08)\end{array}$ & $\begin{array}{l}-0.03 \\
(0.08)\end{array}$ & $\begin{array}{c}0.04 \\
(0.11)\end{array}$ & $\begin{array}{l}-0.09 \\
(0.06)\end{array}$ & $\begin{array}{l}-0.04 \\
(0.03)\end{array}$ & $\begin{array}{c}0.05 \\
(0.07)\end{array}$ \\
\hline Sample size & 970 & 601 & 1571 & 915 & 575 & 1490 \\
\hline
\end{tabular}

Note: Market-clustered standard errors appear in parentheses. ${ }^{*} p<0.1,{ }^{* *} p<0.05,{ }^{* * *} p<0.01$. 
Table 4: Chain Entry, Customer Traffic, and Market Exit for Incumbents

\begin{tabular}{|c|c|c|c|c|}
\hline \multirow[t]{2}{*}{ Dependent variable: } & \multicolumn{2}{|c|}{$\ln ($ Customer Traffic) } & \multicolumn{2}{|c|}{ Market Exit } \\
\hline & (1) & $(2)$ & $(3)$ & (4) \\
\hline Round 2 & $\begin{array}{l}0.19^{* * *} \\
(0.052)\end{array}$ & $\begin{array}{c}0.12^{*} \\
(0.057)\end{array}$ & $\begin{array}{l}-0.021^{* *} \\
(0.0099)\end{array}$ & $\begin{array}{l}-0.031^{* *} \\
(0.015)\end{array}$ \\
\hline Round $2 \cdot$ entry market & $\begin{array}{l}-0.27^{* * *} \\
(0.069)\end{array}$ & $\begin{array}{l}-0.20^{* *} \\
(0.083)\end{array}$ & $\begin{array}{l}-0.006 \\
(0.016)\end{array}$ & $\begin{array}{l}0.0064 \\
(0.021)\end{array}$ \\
\hline Round 3 & $\begin{array}{c}0.26^{* * *} \\
(0.045)\end{array}$ & $\begin{array}{c}0.20 \\
(0.20)\end{array}$ & $\begin{array}{l}-0.042^{* * *} \\
(0.013)\end{array}$ & $\begin{array}{l}-0.086^{* *} \\
(0.033)\end{array}$ \\
\hline Round $3 \cdot$ entry market & $\begin{array}{l}-0.24^{* * *} \\
(0.078)\end{array}$ & $\begin{array}{l}-0.19^{* *} \\
(0.074)\end{array}$ & $\begin{array}{l}-0.055^{* *} \\
(0.026)\end{array}$ & $\begin{array}{l}-0.047^{*} \\
(0.026)\end{array}$ \\
\hline Market demo and health controls & - & Yes & - & Yes \\
\hline Wild bootstrap p-value: & & & & \\
\hline $\begin{array}{l}\text { Round } 2 \cdot \text { entry } \\
\text { Round } 3 \cdot \text { entry }\end{array}$ & $\begin{array}{l}0.00 \\
0.05\end{array}$ & $\begin{array}{l}0.16 \\
0.21\end{array}$ & $\begin{array}{l}0.07 \\
0.03\end{array}$ & $\begin{array}{l}0.01 \\
0.04\end{array}$ \\
\hline Proportional selection $\delta$ : & & & & \\
\hline $\begin{array}{l}\text { Round } 2 \cdot \text { entry } \\
\text { Round } 3 \cdot \text { entry }\end{array}$ & - & $\begin{array}{l}1.11 \\
1.18\end{array}$ & - & $\begin{array}{r}-0.06 \\
0.97\end{array}$ \\
\hline $\begin{array}{l}\text { Observations } \\
R^{2}\end{array}$ & $\begin{array}{l}298 \\
0.26\end{array}$ & $\begin{array}{l}298 \\
0.27\end{array}$ & $\begin{array}{l}1053 \\
0.05\end{array}$ & $\begin{array}{l}1053 \\
0.05\end{array}$ \\
\hline
\end{tabular}

Note: Market-clustered standard errors appear in parentheses. All regressions include market fixed effects.

${ }^{*} p<0.1,{ }^{* *} p<0.05,{ }^{* * *} p<0.01$. 
Table 5: Chain Entry and Incumbent Drug Quality

\begin{tabular}{|c|c|c|c|c|c|c|c|}
\hline \multirow{3}{*}{$\begin{array}{l}\text { Dependent variable: } \\
\text { Manufacturers: }\end{array}$} & \multicolumn{7}{|c|}{ Complies with Indian Pharmacopeia } \\
\hline & \multicolumn{2}{|c|}{ All } & \multicolumn{2}{|c|}{ National } & \multicolumn{3}{|c|}{ Non-National } \\
\hline & $(1)$ & $(2)$ & $(3)$ & $(4)$ & $(5)$ & $(6)$ & $(7)$ \\
\hline Post entry & $\begin{array}{l}-0.043^{* *} \\
(0.019)\end{array}$ & $\begin{array}{l}-0.078^{* * *} \\
(0.013)\end{array}$ & $\begin{array}{l}-0.003 \\
(0.021)\end{array}$ & $\begin{array}{l}-0.063^{* * *} \\
(0.021)\end{array}$ & $\begin{array}{l}-0.15^{* *} \\
(0.058)\end{array}$ & $\begin{array}{l}-0.21^{* * *} \\
(0.062)\end{array}$ & $\begin{array}{c}-0.11 \\
(0.080)\end{array}$ \\
\hline Post entry $\cdot$ entry market & $\begin{array}{c}0.043^{* *} \\
(0.019)\end{array}$ & $\begin{array}{l}0.066^{* * *} \\
(0.017)\end{array}$ & $\begin{array}{l}-0.018 \\
(0.025)\end{array}$ & $\begin{array}{c}0.007 \\
(0.025)\end{array}$ & $\begin{array}{l}0.20^{* * *} \\
(0.067)\end{array}$ & $\begin{array}{l}0.24^{* * *} \\
(0.044)\end{array}$ & $\begin{array}{c}0.15^{*} \\
(0.076)\end{array}$ \\
\hline Market demo and health controls & - & Yes & - & Yes & - & Yes & Yes \\
\hline Manufacturer fixed effects & - & - & - & - & - & - & Yes \\
\hline Wild bootstrap p-value (post · entry) & 0.04 & 0.03 & 0.50 & 0.95 & 0.01 & 0.12 & 0.34 \\
\hline Proportional selection $\delta$ & - & -6.78 & - & -0.42 & - & -0.45 & - \\
\hline Observations & 796 & 796 & 520 & 520 & 276 & 276 & 265 \\
\hline$R^{2}$ & 0.06 & 0.07 & 0.06 & 0.09 & 0.25 & 0.35 & 0.55 \\
\hline
\end{tabular}

Note: Market-clustered standard errors appear in parentheses. All regressions include market fixed effects. ${ }^{*} p<0.1,{ }^{* *} p<0.05,{ }^{* * *} p<0.01$. 
Table 6: The Impact on Quality Components

\begin{tabular}{|c|c|c|c|c|c|c|c|}
\hline \multirow{3}{*}{$\begin{array}{l}\text { Quality Component: } \\
\text { Dependent variable: }\end{array}$} & \multicolumn{3}{|c|}{ Active Ingredient Concentration } & \multicolumn{2}{|c|}{ Dissolution } & \multicolumn{2}{|c|}{ Uniformity } \\
\hline & Raw & Abs. \% Dev. & Pass & Raw & Pass & Raw & Pass \\
\hline & $(1)$ & $(2)$ & $(3)$ & $(4)$ & $(5)$ & $(6)$ & $(7)$ \\
\hline \multicolumn{8}{|l|}{ Panel A: All Manufacturers } \\
\hline Post entry & $\begin{array}{c}-6.86^{* * *} \\
(1.37)\end{array}$ & $\begin{array}{l}0.018 \\
(0.28)\end{array}$ & $\begin{array}{l}-0.018 \\
(0.016)\end{array}$ & $\begin{array}{c}0.11 \\
(0.50)\end{array}$ & $\begin{array}{l}-0.024^{*} \\
(0.013)\end{array}$ & $\begin{array}{c}-0.50^{* * *} \\
(0.081)\end{array}$ & $\begin{array}{l}-0.020^{* *} \\
(0.0092)\end{array}$ \\
\hline Post entry $\cdot$ entry market & $\begin{array}{c}3.53 \\
(2.45)\end{array}$ & $\begin{array}{l}-0.24 \\
(0.37)\end{array}$ & $\begin{array}{l}0.042^{* *} \\
(0.019)\end{array}$ & $\begin{array}{c}1.30 \\
(0.89)\end{array}$ & $\begin{array}{c}0.032^{*} \\
(0.015)\end{array}$ & $\begin{array}{l}-0.11 \\
(0.18)\end{array}$ & $\begin{array}{c}-0.0036 \\
(0.014)\end{array}$ \\
\hline Wild bootstrap p-value (post · entry) & 0.20 & 0.53 & 0.05 & 0.19 & 0.05 & 0.56 & 0.80 \\
\hline \multicolumn{8}{|l|}{ Panel B: Non-National Manufacturers } \\
\hline Post entry & $\begin{array}{c}-9.21^{* *} \\
(3.27)\end{array}$ & $\begin{array}{l}1.69^{* *} \\
(0.61)\end{array}$ & $\begin{array}{l}-0.12^{* * *} \\
(0.035)\end{array}$ & $\begin{array}{l}-0.90 \\
(1.42)\end{array}$ & $\begin{array}{l}-0.050 \\
(0.033)\end{array}$ & $\begin{array}{c}-0.64^{* * *} \\
(0.17)\end{array}$ & $\begin{array}{l}-0.029 \\
(0.030)\end{array}$ \\
\hline Post entry $\cdot$ entry market & $\begin{array}{c}1.06 \\
(4.94)\end{array}$ & $\begin{array}{c}-2.10^{* *} \\
(0.83)\end{array}$ & $\begin{array}{l}0.18^{* * *} \\
(0.055)\end{array}$ & $\begin{array}{l}3.76^{*} \\
(2.01)\end{array}$ & $\begin{array}{c}0.11^{* *} \\
(0.045)\end{array}$ & $\begin{array}{r}-0.093 \\
(0.23)\end{array}$ & $\begin{array}{r}0.0026 \\
(0.039)\end{array}$ \\
\hline Wild bootstrap p-value (post · entry) & 0.82 & 0.01 & $<0.01$ & 0.09 & 0.03 & 0.69 & 0.93 \\
\hline
\end{tabular}

Note: Market-clustered standard errors appear in parentheses. All regressions include market fixed effects. ${ }^{*} p<0.1,{ }^{* *} p<0.05,{ }^{* * *} p<0.01$. 
Table 7: The Impact of Chain Entry on Prices

\begin{tabular}{|c|c|c|c|c|c|c|c|}
\hline \multirow{3}{*}{$\begin{array}{l}\text { Dependent variable: } \\
\text { Manufacturers: }\end{array}$} & \multicolumn{7}{|c|}{$\ln$ (Price per Tablet) } \\
\hline & \multicolumn{2}{|c|}{ All } & \multicolumn{2}{|c|}{ National } & \multicolumn{3}{|c|}{ Non-National } \\
\hline & (1) & $(2)$ & $(3)$ & $(4)$ & $(5)$ & $(6)$ & $(7)$ \\
\hline Post entry & $\begin{array}{l}0.0047 \\
(0.024)\end{array}$ & $\begin{array}{c}0.019 \\
(0.031)\end{array}$ & $\begin{array}{l}-0.016 \\
(0.022)\end{array}$ & $\begin{array}{l}-0.016 \\
(0.032)\end{array}$ & $\begin{array}{c}0.046 \\
(0.047)\end{array}$ & $\begin{array}{c}0.045 \\
(0.051)\end{array}$ & $\begin{array}{c}0.049 \\
(0.074)\end{array}$ \\
\hline Post entry $\cdot$ entry market & $\begin{array}{l}-0.024 \\
(0.030)\end{array}$ & $\begin{array}{l}-0.040 \\
(0.040)\end{array}$ & $\begin{array}{c}0.021 \\
(0.036)\end{array}$ & $\begin{array}{c}0.037 \\
(0.046)\end{array}$ & $\begin{array}{l}-0.12^{* *} \\
(0.053)\end{array}$ & $\begin{array}{l}-0.15^{* *} \\
(0.066)\end{array}$ & $\begin{array}{l}-0.15 \\
(0.089)\end{array}$ \\
\hline Market demo and health controls & - & Yes & - & Yes & - & Yes & Yes \\
\hline Manufacturer fixed effects & - & - & - & - & - & - & Yes \\
\hline Wild bootstrap p-value (post · entry) & 0.53 & 0.49 & 0.57 & 0.59 & 0.07 & 0.19 & 0.21 \\
\hline Proportional selection $\delta$ & - & -0.69 & - & -0.49 & - & -0.10 & - \\
\hline Observations & 787 & 787 & 520 & 520 & 267 & 267 & 265 \\
\hline$R^{2}$ & 0.124 & 0.130 & 0.155 & 0.161 & 0.180 & 0.221 & 0.658 \\
\hline
\end{tabular}

Note: Market-clustered standard errors appear in parentheses. ${ }^{*} p<0.1,{ }^{* *} p<0.05,{ }^{* * *} p<0.01$. 
Table 8: Robustness to Unobservable Trends

\begin{tabular}{|c|c|c|c|c|c|c|c|c|}
\hline \multirow[t]{2}{*}{ Dependent variable: } & \multicolumn{4}{|c|}{ Complies with IP } & \multicolumn{4}{|c|}{$\ln$ (Price per Tablet) } \\
\hline & $(1)$ & $(2)$ & $(3)$ & $(4)$ & $(5)$ & $(6)$ & $(7)$ & $(8)$ \\
\hline Post entry & $\begin{array}{l}-1.91 \\
(1.49)\end{array}$ & $\begin{array}{c}-0.032 \\
(0.31)\end{array}$ & $\begin{array}{l}-0.82^{* *} \\
(0.37)\end{array}$ & $\begin{array}{l}0.57^{\text {*** }} \\
(0.17)\end{array}$ & $\begin{array}{l}-2.18^{*} \\
(1.11)\end{array}$ & $\begin{array}{c}0.24 \\
(0.17)\end{array}$ & $\begin{array}{l}-0.63^{* *} \\
(0.26)\end{array}$ & $\begin{array}{c}0.55^{* * *} \\
(0.16)\end{array}$ \\
\hline Post entry $\cdot$ entry market & $\begin{array}{c}0.22^{* *} \\
(0.082)\end{array}$ & $\begin{array}{c}0.16^{* *} \\
(0.058)\end{array}$ & $\begin{array}{c}0.14^{* * *} \\
(0.047)\end{array}$ & $\begin{array}{c}0.19^{* *} \\
(0.068)\end{array}$ & $\begin{array}{l}-0.20^{* * *} \\
(0.065)\end{array}$ & $\begin{array}{c}-0.13^{* *} \\
(0.057)\end{array}$ & $\begin{array}{c}-0.096 \\
(0.062)\end{array}$ & $\begin{array}{c}-0.084^{*} \\
(0.046)\end{array}$ \\
\hline \multicolumn{9}{|l|}{ Post entry · baseline: } \\
\hline$\overline{\text {-Market demographic }}$ controls & Yes & - & - & - & Yes & - & - & - \\
\hline -Market health controls & - & Yes & - & - & - & Yes & - & - \\
\hline -Pharmacy characteristics & - & - & Yes & - & - & - & Yes & - \\
\hline -Dependent variable (pharm. mean) & - & - & - & Yes & - & - & - & Yes \\
\hline Wild bootstrap p-value (post $\cdot$ entry) & 0.07 & 0.02 & 0.02 & 0.01 & 0.10 & 0.07 & 0.36 & 0.08 \\
\hline Proportional selection $\delta$ & -3.94 & 0.71 & 1.21 & 1.05 & -0.54 & -0.72 & 1.76 & 4.12 \\
\hline Observations & 271 & 271 & 269 & 271 & 261 & 261 & 259 & 261 \\
\hline$R^{2}$ & 0.27 & 0.28 & 0.34 & 0.28 & 0.21 & 0.20 & 0.25 & 0.43 \\
\hline
\end{tabular}

Note: Market-clustered standard errors appear in parentheses. All regressions include market fixed effects. All regressions are limited to the sample of non-national brands. ${ }^{*} p<0.1,{ }^{* *} p<0.05,{ }^{* * *} p<0.01$. 
Table 9: Chain Entry and Perceived Quality

\begin{tabular}{|c|c|c|c|c|c|c|}
\hline \multirow[t]{3}{*}{ Dependent variable: } & \multicolumn{6}{|c|}{ Perceived quality of: } \\
\hline & \multicolumn{2}{|c|}{ Nearby pharms } & \multicolumn{2}{|c|}{ National brands } & \multicolumn{2}{|c|}{ Local brands } \\
\hline & $(1)$ & $(2)$ & $(3)$ & $(4)$ & $(5)$ & $(6)$ \\
\hline Round $2 \cdot$ entry market & $\begin{array}{c}0.081 \\
(0.095)\end{array}$ & $\begin{array}{c}0.19 \\
(0.11)\end{array}$ & $\begin{array}{c}0.19 \\
(0.20)\end{array}$ & $\begin{array}{l}0.49^{* *} \\
(0.21)\end{array}$ & $\begin{array}{c}0.37 \\
(0.26)\end{array}$ & $\begin{array}{c}0.62^{* *} \\
(0.26)\end{array}$ \\
\hline Round $3 \cdot$ entry market & $\begin{array}{c}0.10^{* *} \\
(0.046)\end{array}$ & $\begin{array}{r}0.17^{* *} \\
(0.065)\end{array}$ & $\begin{array}{l}-0.13 \\
(0.10)\end{array}$ & $\begin{array}{c}0.10 \\
(0.16)\end{array}$ & $\begin{array}{c}0.28^{* *} \\
(0.14)\end{array}$ & $\begin{array}{c}0.52^{* * *} \\
(0.13)\end{array}$ \\
\hline Market demo and health controls & - & Yes & - & Yes & - & Yes \\
\hline $\begin{array}{l}\text { Wild bootstrap p-value: } \\
\text { Round } 2 \cdot \text { entry } \\
\text { Round } 3 \cdot \text { entry }\end{array}$ & $\begin{array}{l}0.44 \\
0.05\end{array}$ & $\begin{array}{c}0.20 \\
0.004\end{array}$ & $\begin{array}{l}0.39 \\
0.26\end{array}$ & $\begin{array}{l}0.10 \\
0.57\end{array}$ & $\begin{array}{l}0.20 \\
0.05\end{array}$ & $\begin{array}{c}0.08 \\
0.002\end{array}$ \\
\hline $\begin{array}{l}\text { Proportional selection } \delta \text { : } \\
\text { Round } 2 \cdot \text { entry } \\
\text { Round } 3 \cdot \text { entry }\end{array}$ & - & $\begin{array}{l}-0.48 \\
-0.63\end{array}$ & - & $\begin{array}{l}-1.14 \\
-0.19 \\
\end{array}$ & - & $\begin{array}{l}-1.91 \\
-1.69\end{array}$ \\
\hline $\begin{array}{l}\text { Observations } \\
R^{2}\end{array}$ & $\begin{array}{l}2143 \\
0.05\end{array}$ & $\begin{array}{c}2143 \\
0.05\end{array}$ & $\begin{array}{l}1677 \\
0.11\end{array}$ & $\begin{array}{l}1677 \\
0.16\end{array}$ & $\begin{array}{l}1505 \\
0.19\end{array}$ & $\begin{array}{l}1505 \\
0.23\end{array}$ \\
\hline
\end{tabular}

Note: Market-clustered standard errors appear in parentheses. All regressions include market fixed effects. Dependent variables are measured on a scale of 1 (low) to 4 (high). Estimates are for non-shoppers. ${ }^{*} p<0.1,{ }^{* *} p<0.05,{ }^{* * *} p<0.01$. 
Table 10: Quality and Prices in Entry Markets

\begin{tabular}{|c|c|c|c|c|}
\hline \multirow{2}{*}{$\begin{array}{l}\text { Sample: } \\
\text { Dependent variable: }\end{array}$} & \multicolumn{2}{|c|}{ Overall } & \multicolumn{2}{|c|}{ Common Brands } \\
\hline & $\frac{\text { Quality }}{(1)}$ & $\frac{\ln (\text { Price })}{(2)}$ & $\frac{\text { Quality }}{(3)}$ & $\frac{\ln (\text { Price })}{(4)}$ \\
\hline Chain pharmacy & $\begin{array}{c}-0.0068 \\
(0.032)\end{array}$ & $\begin{array}{l}-0.061 \\
(0.037)\end{array}$ & $\begin{array}{c}0.051 \\
(0.051)\end{array}$ & $\begin{array}{c}-0.090^{* *} \\
(0.032)\end{array}$ \\
\hline Wild bootstrap p-value (Chain pharmacy) & 0.80 & 0.17 & 0.49 & 0.05 \\
\hline $\begin{array}{l}\text { Observations } \\
R^{2}\end{array}$ & $\begin{array}{c}361 \\
0.00\end{array}$ & $\begin{array}{l}359 \\
0.01\end{array}$ & $\begin{array}{c}98 \\
0.01\end{array}$ & $\begin{array}{c}98 \\
0.24\end{array}$ \\
\hline
\end{tabular}

Note: Market-clustered standard errors appear in parentheses. The regressions in Columns 3 and 4 only include brands that both the chain and incumbents carry. ${ }^{*} p<0.1,{ }^{* *} p<0.05,{ }^{* * *} p<0.01$. 
Table 11: The Market-wide Impact of Chain Entry

\begin{tabular}{|c|c|c|c|c|c|c|c|c|}
\hline \multirow[t]{2}{*}{ Dependent variable: } & \multicolumn{4}{|c|}{ Complies with IP } & \multicolumn{4}{|c|}{$\ln$ (Price per Tablet) } \\
\hline & (1) & $(2)$ & $(3)$ & (4) & $(5)$ & (6) & $(7)$ & (8) \\
\hline \multicolumn{9}{|l|}{ Post entry · entry market: } \\
\hline- & $\begin{array}{l}0.049^{* *} \\
(0.021)\end{array}$ & $\begin{array}{c}0.068^{* * *} \\
(0.021)\end{array}$ & $\begin{array}{c}0.023 \\
(0.026)\end{array}$ & $\begin{array}{c}0.054 \\
(0.037)\end{array}$ & $\begin{array}{l}-0.055 \\
(0.035)\end{array}$ & $\begin{array}{c}-0.073^{*} \\
(0.036)\end{array}$ & $\begin{array}{c}-0.043 \\
(0.052)\end{array}$ & $\begin{array}{l}-0.055 \\
(0.041)\end{array}$ \\
\hline · high-education customers & & & $\begin{array}{c}0.048 \\
(0.035)\end{array}$ & & & & $\begin{array}{l}-0.017 \\
(0.066)\end{array}$ & \\
\hline · high-SES mystery shopper & & & & $\begin{array}{l}-0.010 \\
(0.064)\end{array}$ & & & & $\begin{array}{c}0.00021 \\
(0.036)\end{array}$ \\
\hline Market demo and health controls & - & Yes & - & - & - & Yes & - & - \\
\hline \multicolumn{9}{|l|}{ Wild bootstrap p-value: } \\
\hline Post $\cdot$ entry & 0.03 & 0.05 & 0.27 & 0.17 & 0.16 & 0.13 & 0.77 & 0.21 \\
\hline Post $\cdot$ entry $\cdot$ customer educ. & - & - & 0.71 & - & - & - & 0.13 & - \\
\hline Post $\cdot$ entry $\cdot$ shopper SES & - & - & - & 0.89 & - & - & - & 0.87 \\
\hline Proportional selection $\delta$ & - & -2.37 & - & - & - & -0.16 & - & - \\
\hline Observations & 824 & 824 & 824 & 824 & 813 & 813 & 813 & 813 \\
\hline$R^{2}$ & 0.057 & 0.069 & 0.058 & 0.059 & 0.135 & 0.146 & 0.141 & 0.138 \\
\hline
\end{tabular}

Note: Market-clustered standard errors appear in parentheses. All regressions include market fixed effects. ${ }^{*} p<0.1,{ }^{* *} p<0.05,{ }^{* * *} p<0.01$. 


\section{A Appendix}

\section{A.1 Differences Between Treatment and Control Markets}

This subsection explores three potential differences between treatment and control markets. First, our sample includes two control markets that were not candidate entry markets. Consumers in these markets have lower socioeconomic status, with 23 percent lower household income and 1.7 fewer years of schooling ( $p<0.01$ for both variables). We include these markets in our baseline estimates to improve precision. Appendix Table 1 reproduces our main results while excluding these markets. Quality results appear in Columns 1 through 4 and price results appear in Columns 5 through 8. We report all estimates with and without demographic and economic controls. Point estimates closely resemble the baseline estimates in Tables 5 and 7, however standard errors are around 15 percent large. The similarity of these results indicates that our findings are not sensitive to whether these markets are included.

Secondly, Figure 4 shows that treatment markets appear to be located further from the city center. The average distance to the city center is $13.0 \mathrm{~km}$ for treatment markets and $9.6 \mathrm{~km}$ for control markets, which not statistically different $(p=0.19)$. Moreover, the city center of Hyderabad is not necessarily a meaningful economic reference point because the metropolitan area also includes the twin city of Secunderabad to the north. The comparison of treatment and control markets in Table 2 provides a better indication of market demand. Nevertheless, Panel A of Appendix Table 2 assesses the robustness to distance heterogeneity in two ways. Odd columns repeat the quality and price regressions from Tables 5 and 7 but control for the interaction between Post and distance to the city center. Both quality and price estimates resemble, which suggests that distance heterogeneity does not contribute to our results. Even columns limit the sample to candidate markets that have similar distances by dropping the five markets closest to the center. Quality results closely resemble baseline estimates while price results are similar but smaller. 
Next we compare the growth in customer traffic in treatment and control markets after accounting for chain traffic. Table 4 excludes the chain in order to focus on the impact for incumbents. As another test of the identifying assumption, we include chain traffic in order to compare total traffic growth in treatment and control markets. This exercise is not straightforward for several reasons. We only observe traffic for a subset of each market's pharmacies, which creates measurement error for market-wide traffic estimates. Secondly, our consumer survey indicates that chain shoppers purchase 25 percent more medicine by volume than incumbent shoppers.

Nevertheless, we examine traffic growth by treatment status, and find that traffic growth is slightly lower but insignificantly different in treatment markets once we include traffic at the chain. Traffic in treatment markets is 3 percent lower in Round $1(p=0.75), 12$ percent lower in Round $2(p=0.15)$, and 8 percent lower in Round $3(p=0.40)$. We account for heterogeneity across stores in the quantity per customer using estimates from our consumer survey. Scaling customer traffic by the average quantity per customer does not change these estimates but cause the differences by treatment status to become highly insignificant $(p>0.5)$.

Panel B of Appendix Table 2 explores whether unobservables correlated with traffic growth confound our estimates. As above, odd columns control for the interaction between Post $_{t}$ and market-wide traffic growth. If growth in customer traffic is correlated with unobservable determinants of quality and price, this approach should change the treatment effect estimates. However estimates closely resemble the baseline results in Tables 5 and 7. Even columns restrict the sample to 14 markets for which traffic growth is comparable across treatment and control markets. ${ }^{26}$ There is no difference in average traffic growth across treatment and control markets under this restriction. The table shows that quality results closely resemble our baseline estimates. Price results are weaker but are qualitatively similar to our main findings. These results suggest that unobservables correlated with traffic

\footnotetext{
${ }^{26}$ We restrict the sample to markets for which the change in traffic from Round 1 to Round 2 ranges from -61 to 85 , which excludes several high-growth control markets.
} 
growth do not confound our results.

\section{A.2 Quality Signaling}

We argue in Section 5.4 that treatment incumbents improve quality in order to compete with the chain. For this mechanism to explain our findings, consumers must perceive and reward incumbents for quality improvements. Table 9 shows that consumers perceive higher quality after chain entry, but it is unclear how firms communicate this information. An industrial organization literature considers how firms signal quality in theory (e.g. Nelson 1974, Allen 1984), but no studies (to our knowledge) address whether or how firms signal in this market. Pharmacies may make costly investments such as air conditioning, advertise, or improve visible product attributes. Alternatively, they may communicate directly to consumers, relying on repeated interaction to establish credibility.

This subsection shows the effect of chain entry on incumbent signaling behavior. Our survey records the tidiness of the store, whether the store has air conditioning, and the number of storefront signs. We also track the packaging condition and the days until expiry for samples in the mystery shopper audit. Appendix Table 4 shows the effect of chain entry on these outcomes. Estimates are mixed and statistically insignificant. In the strongest result, chain entry is associated with an increase of 0.4 incumbent signs, although this result is not significant.

We may fail to find effects for several reasons. Firms may not signal through any of these channels. Margins like air conditioning and the tidiness of the physical space may be difficult to adjust in the short run. Signaling by the pharmacist - for example, through more productive customer service, or non-productive advertising - may be a more relevant in the short run, but were not measured in our study. Similarly, commercial advertising, by the

pharmacies or local brand manufacturers, through local print media was not measured, but may be another mechanism by which suppliers signal quality improvements. 


\section{A.3 Treatment Spillovers}

This subsection discusses the possibility that chain entry could indirectly affect prices and quality in control markets. We proxy for markets spatially using the area within a 0.5 kilometer radius from the candidate entry site. Markets do not overlap or share borders. For control markets, the closest treatment market is an average of 8.1 kilometers away and a minimum of 2.4 kilometers away, suggesting that spillovers are unlikely. More formally, Appendix Table 5 tests whether results are sensitive to the proximity of treatment and control markets by excluding nearby control markets from the analysis. Odd columns exclude four control markets that are within 5 kilometers of a treatment market while even columns exclude eight control markets that are within 10 kilometers of a treatment market. The remaining control markets are an average of 10 kilometers away from a treatment market under the first restriction and 12 kilometers away under the second restriction. Estimates in the table closely resemble our baseline estimates, suggesting that treatment spillovers do not confound our results.

\section{A.4 Changes over Time for Non-National Brands}

Treatment effect estimates for non-national brands are identified through changes over time in quality and price within this subsample. To clarify this source of variation, Appendix Figure 1 reproduces the plots in Figure 6 for non-national manufacturers. Pharmacopeia compliance is initially 5 percentage points higher in control markets $(p=0.22)$. The nonnational treatment effect estimate of 0.20 (Column 5 of Table 5 ) is based on a 5 percentage point quality improvement in treatment markets over time and a 15 percentage point deterioration in control markets. As we discuss previously, the secular decline in quality is most likely caused by the marked increased in both humidity and temperature during the second survey round. Prices are initially 8.4 percent higher in treatment markets $(p=0.09)$. The 12 percent price decline (Column 5 of Table 7 ) is based on a 5 percent increase in control markets and a 7 percent decrease in treatment markets. 


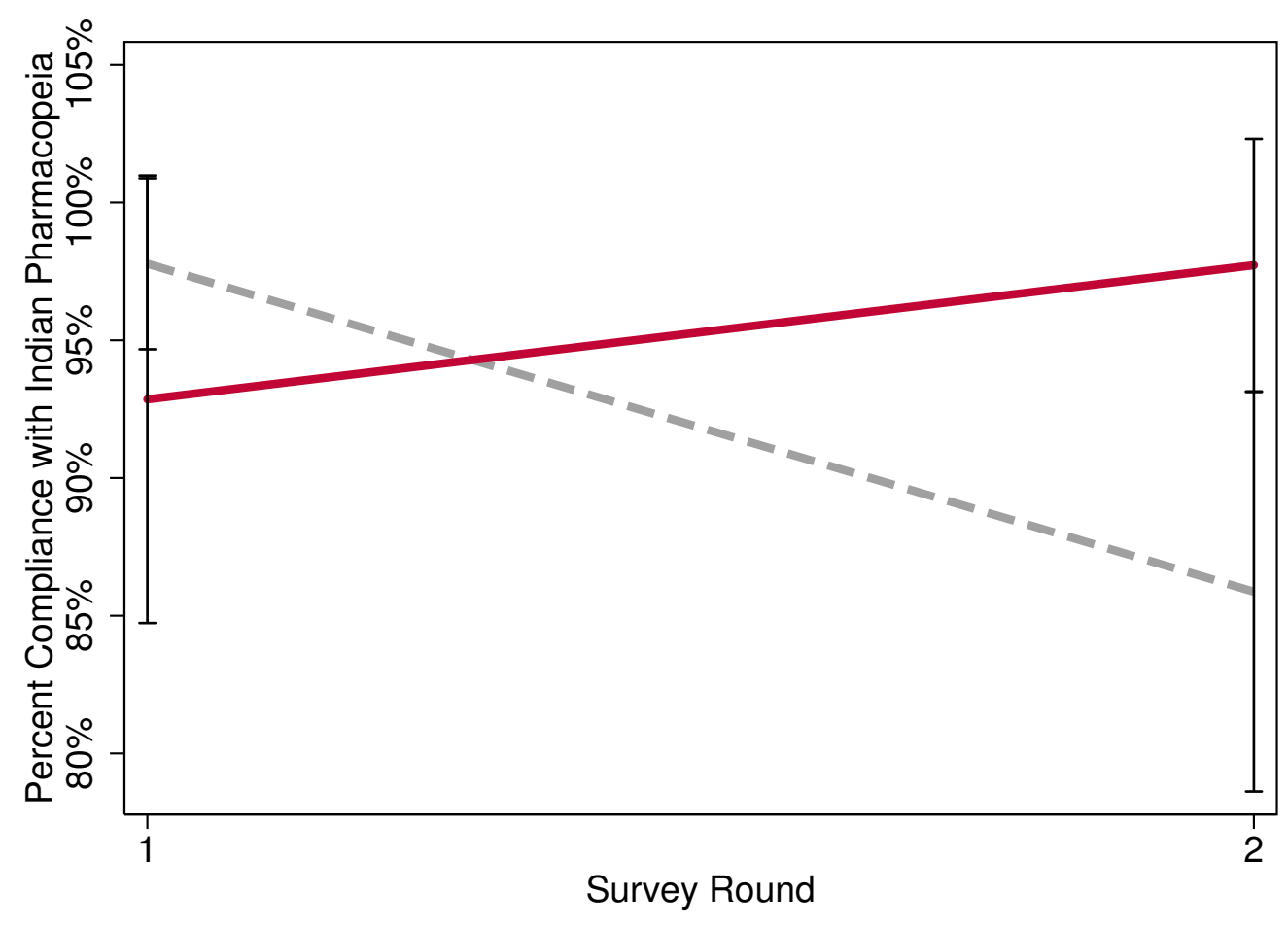

- - - Control Markets _ Treatment Markets

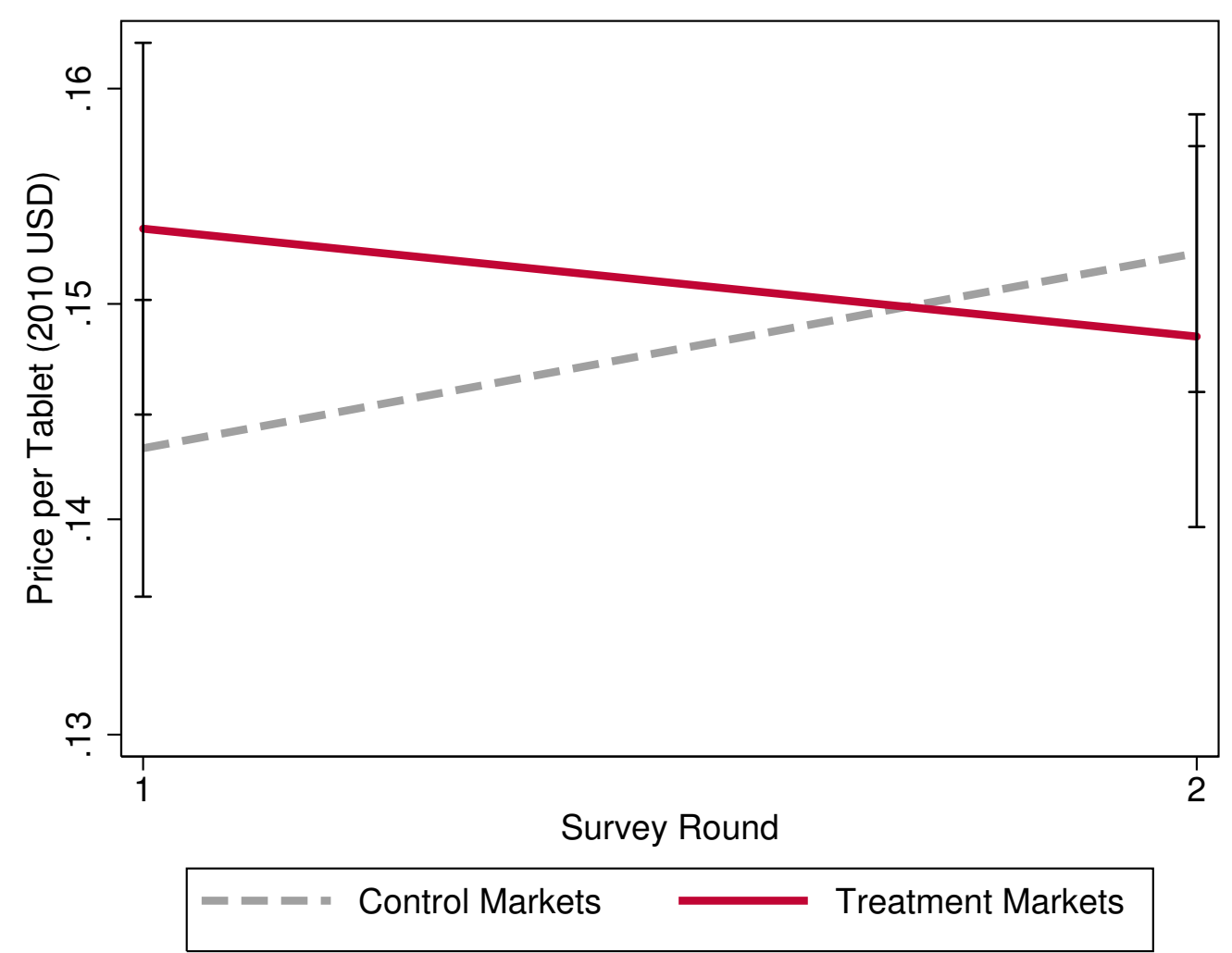

Appendix Figure 1: Quality and Price Changes for Non-National Drug Samples 
Appendix Table 1: Estimates for 18 Candidate Entry Markets

\begin{tabular}{|c|c|c|c|c|c|c|c|c|}
\hline & \multicolumn{4}{|c|}{ Complies with Indian Pharmacopeia } & \multicolumn{4}{|c|}{$\ln ($ Price per Tablet $)$} \\
\hline & \multicolumn{2}{|c|}{ All } & \multicolumn{2}{|c|}{ Non-National } & \multicolumn{2}{|c|}{ All } & \multicolumn{2}{|c|}{ Non-National } \\
\hline & $(1)$ & $(2)$ & $(3)$ & $(4)$ & $(5)$ & $(6)$ & $(7)$ & $(8)$ \\
\hline Post entry & $\begin{array}{l}-0.046^{*} \\
(0.022)\end{array}$ & $\begin{array}{l}-0.066^{* * *} \\
(0.016)\end{array}$ & $\begin{array}{c}-0.17^{* *} \\
(0.071)\end{array}$ & $\begin{array}{c}-0.15^{*} \\
(0.086)\end{array}$ & $\begin{array}{c}0.0008 \\
(0.025)\end{array}$ & $\begin{array}{c}0.002 \\
(0.033)\end{array}$ & $\begin{array}{c}0.059 \\
(0.057)\end{array}$ & $\begin{array}{c}0.18^{* *} \\
(0.067)\end{array}$ \\
\hline Post entry $\cdot$ entry market & $\begin{array}{c}0.046^{*} \\
(0.022)\end{array}$ & $\begin{array}{c}0.053^{* *} \\
(0.023)\end{array}$ & $\begin{array}{c}0.22^{* *} \\
(0.077)\end{array}$ & $\begin{array}{c}0.15^{*} \\
(0.083)\end{array}$ & $\begin{array}{c}-0.019 \\
(0.031)\end{array}$ & $\begin{array}{c}-0.036 \\
(0.045)\end{array}$ & $\begin{array}{c}-0.11^{*} \\
(0.062)\end{array}$ & $\begin{array}{l}-0.27^{* * *} \\
(0.071)\end{array}$ \\
\hline Market demo and health controls & - & Yes & - & Yes & - & Yes & - & Yes \\
\hline Wild bootstrap p-value (post · entry) & 0.05 & 0.19 & 0.01 & 0.30 & 0.55 & 0.58 & 0.09 & 0.06 \\
\hline Proportional selection $\delta$ & - & -0.52 & - & 1.84 & - & -0.02 & - & -3.27 \\
\hline Observations & 716 & 716 & 235 & 235 & 708 & 708 & 228 & 228 \\
\hline$R^{2}$ & 0.07 & 0.08 & 0.26 & 0.37 & 0.11 & 0.11 & 0.17 & 0.25 \\
\hline
\end{tabular}

다 Note: Market-clustered standard errors appear in parentheses. All regressions include market fixed effects. ${ }^{*} p<0.1,{ }^{* *} p<0.05,{ }^{* * *} p<0.01$. 
Appendix Table 2: Additional Robustness Tests

\begin{tabular}{|c|c|c|c|c|c|c|c|c|}
\hline \multirow{3}{*}{ Manufacturers: } & \multicolumn{4}{|c|}{ Complies with Indian Pharmacopeia } & \multicolumn{4}{|c|}{$\ln ($ Price per Tablet) } \\
\hline & \multicolumn{2}{|c|}{ All } & \multicolumn{2}{|c|}{ Non-National } & \multicolumn{2}{|c|}{ All } & \multicolumn{2}{|c|}{ Non-National } \\
\hline & $(1)$ & $(2)$ & $(3)$ & $(4)$ & $(5)$ & $(6)$ & $(7)$ & $(8)$ \\
\hline \multicolumn{9}{|l|}{ Panel A: Distance to Center } \\
\hline Post entry $\cdot$ entry market & $\begin{array}{c}0.058^{* * *} \\
(0.018) \\
{[0.00]}\end{array}$ & $\begin{array}{c}0.057^{* *} \\
(0.026) \\
{[0.04]}\end{array}$ & $\begin{array}{c}0.22^{* * *} \\
(0.070) \\
{[0.00]}\end{array}$ & $\begin{array}{c}0.24^{* *} \\
(0.10) \\
{[0.01]}\end{array}$ & $\begin{array}{c}-0.042 \\
(0.026) \\
{[0.15]}\end{array}$ & $\begin{array}{c}-0.0006 \\
(0.030) \\
{[0.98]}\end{array}$ & $\begin{array}{c}-0.093^{*} \\
(0.051) \\
{[0.14]}\end{array}$ & $\begin{array}{c}-0.046 \\
(0.051) \\
{[0.36]}\end{array}$ \\
\hline Control for Post $\cdot$ Distance & Yes & - & Yes & - & Yes & - & Yes & - \\
\hline Comparable distance sample & - & Yes & - & Yes & - & Yes & - & Yes \\
\hline Observations & 796 & 596 & 268 & 188 & 788 & 593 & 261 & 185 \\
\hline \multicolumn{9}{|l|}{ Panel B: Traffic Growth } \\
\hline Post entry $\cdot$ entry market & $\begin{array}{c}0.038^{*} \\
(0.018) \\
{[0.04]}\end{array}$ & $\begin{array}{c}0.050^{*} \\
(0.028) \\
{[0.10]}\end{array}$ & $\begin{array}{c}0.22^{* * *} \\
(0.075) \\
{[0.01]}\end{array}$ & $\begin{array}{c}0.25^{* *} \\
(0.11) \\
{[0.01]}\end{array}$ & $\begin{array}{c}-0.050 \\
(0.030) \\
{[0.14]}\end{array}$ & $\begin{array}{c}-0.061 \\
(0.035) \\
{[0.12]}\end{array}$ & $\begin{array}{c}-0.11^{*} \\
(0.053) \\
{[0.06]}\end{array}$ & $\begin{array}{c}-0.057 \\
(0.052) \\
{[0.28]}\end{array}$ \\
\hline Control for Post $\cdot$ Growth & Yes & - & Yes & - & Yes & - & Yes & - \\
\hline Comparable growth rate sample & - & Yes & - & Yes & - & Yes & - & Yes \\
\hline Observations & 796 & 557 & 268 & 186 & 788 & 554 & 261 & 183 \\
\hline
\end{tabular}

Note: Market-clustered standard errors appear in parentheses and wild-cluster bootstrap p-values appear in brackets. All regressions include market fixed effects. ${ }^{*} p<0.1,{ }^{* *} p<0.05,{ }^{* * *} p<0.01$. 
Appendix Table 3: Chain Entry and Incumbent Shopper Characteristics

\begin{tabular}{|c|c|c|c|c|c|}
\hline Dependent variable: & $\frac{\ln (\text { Income })}{(1)}$ & $\frac{\text { Education }}{(2)}$ & $\begin{array}{c}\begin{array}{c}\text { Household } \\
\text { size }\end{array} \\
(3)\end{array}$ & $\begin{array}{c}\text { Scheduled } \\
\text { caste/tribe } \\
(4)\end{array}$ & $\begin{array}{c}\text { Owns a } \\
\text { vehicle } \\
(5)\end{array}$ \\
\hline Round $2 \cdot$ entry market & $\begin{array}{r}-0.045 \\
(0.17)\end{array}$ & $\begin{array}{l}-0.41 \\
(1.00)\end{array}$ & $\begin{array}{c}0.18 \\
(0.23)\end{array}$ & $\begin{array}{l}-0.010 \\
(0.079)\end{array}$ & $\begin{array}{l}0.033 \\
(0.13)\end{array}$ \\
\hline Round $3 \cdot$ entry market & $\begin{array}{c}0.0085 \\
(0.14)\end{array}$ & $\begin{array}{r}-0.033 \\
(0.86)\end{array}$ & $\begin{array}{l}-0.27 \\
(0.17)\end{array}$ & $\begin{array}{l}-0.027 \\
(0.056)\end{array}$ & $\begin{array}{c}0.084 \\
(0.097)\end{array}$ \\
\hline \multicolumn{6}{|l|}{ Wild bootstrap p-value } \\
\hline $\begin{array}{l}\text { Round } 2 \cdot \text { entry } \\
\text { Round } 3 \cdot \text { entry }\end{array}$ & $\begin{array}{l}0.81 \\
0.96\end{array}$ & $\begin{array}{l}0.73 \\
0.97\end{array}$ & $\begin{array}{l}0.45 \\
0.16\end{array}$ & $\begin{array}{l}0.90 \\
0.62\end{array}$ & $\begin{array}{l}0.82 \\
0.42\end{array}$ \\
\hline $\begin{array}{l}\text { Observations } \\
R^{2}\end{array}$ & $\begin{array}{c}2224 \\
0.06\end{array}$ & $\begin{array}{c}2224 \\
0.06\end{array}$ & $\begin{array}{c}2224 \\
0.07\end{array}$ & $\begin{array}{c}2224 \\
0.03\end{array}$ & $\begin{array}{c}2224 \\
0.04\end{array}$ \\
\hline
\end{tabular}

g macies. All regressions include market fixed effects. ${ }^{*} p<0.1,{ }^{* *} p<0.05$, *** $p<0.01$. 
Appendix Table 4: Chain Entry and Observable Signaling by Incumbents

\begin{tabular}{|c|c|c|c|c|c|}
\hline Dependent variable: & $\begin{array}{c}\text { Pharmacy } \\
\text { Cleanliness } \\
(1)\end{array}$ & $\begin{array}{c}\text { Number } \\
\text { of Signs } \\
(2)\end{array}$ & $\begin{array}{c}\text { Air } \\
\text { Conditioning } \\
(3)\end{array}$ & $\begin{array}{c}\text { Days Until } \\
\text { Expiry } \\
(4)\end{array}$ & $\begin{array}{c}\text { Packaging } \\
\text { Condition } \\
(5)\end{array}$ \\
\hline Post entry & $\begin{array}{c}-0.034 \\
(0.082)\end{array}$ & $\begin{array}{l}0.050 \\
(0.20)\end{array}$ & $\begin{array}{l}-0.034 \\
(0.032)\end{array}$ & $\begin{array}{c}3.53 \\
(23.5)\end{array}$ & $\begin{array}{l}-0.22^{* * *} \\
(0.072)\end{array}$ \\
\hline Post entry $\cdot$ entry market & $\begin{array}{l}-0.17 \\
(0.14)\end{array}$ & $\begin{array}{c}0.35 \\
(0.27)\end{array}$ & $\begin{array}{c}0.034 \\
(0.032)\end{array}$ & $\begin{array}{l}-18.1 \\
(28.8)\end{array}$ & $\begin{array}{c}-0.045 \\
(0.11)\end{array}$ \\
\hline Wild bootstrap p-value (post · entry) & 0.24 & 0.20 & 0.28 & 0.54 & 0.71 \\
\hline $\begin{array}{l}\text { Observations } \\
R^{2}\end{array}$ & $\begin{array}{c}199 \\
0.142\end{array}$ & $\begin{array}{c}199 \\
0.408\end{array}$ & $\begin{array}{c}199 \\
0.265\end{array}$ & $\begin{array}{l}1605 \\
0.022\end{array}$ & $\begin{array}{l}1642 \\
0.105\end{array}$ \\
\hline
\end{tabular}


Appendix Table 5: A Test for Treatment Spillovers into Control Markets

\begin{tabular}{|c|c|c|c|c|c|c|c|c|}
\hline \multirow{3}{*}{$\begin{array}{l}\text { Dependent variable } \\
\text { Manufacturers }\end{array}$} & \multicolumn{4}{|c|}{ Complies with IP } & \multicolumn{4}{|c|}{$\ln$ (Price per Tablet) } \\
\hline & \multicolumn{2}{|c|}{ All } & \multicolumn{2}{|c|}{ Non-National } & \multicolumn{2}{|c|}{ All } & \multicolumn{2}{|c|}{ Non-National } \\
\hline & $(1)$ & $(2)$ & $(3)$ & $(4)$ & $(5)$ & $(6)$ & (7) & $(8)$ \\
\hline Post & $\begin{array}{l}-0.044 \\
(0.026)\end{array}$ & $\begin{array}{l}-0.070^{*} \\
(0.036)\end{array}$ & $\begin{array}{l}-0.18^{* *} \\
(0.085)\end{array}$ & $\begin{array}{l}-0.25 \\
(0.15)\end{array}$ & $\begin{array}{c}0.034 \\
(0.029)\end{array}$ & $\begin{array}{c}0.043 \\
(0.037)\end{array}$ & $\begin{array}{c}0.10 \\
(0.067)\end{array}$ & $\begin{array}{c}0.17^{*} \\
(0.094)\end{array}$ \\
\hline Post $\cdot$ entry market & $\begin{array}{c}0.045 \\
(0.026)\end{array}$ & $\begin{array}{l}0.071^{*} \\
(0.036)\end{array}$ & $\begin{array}{r}0.24^{* *} \\
(0.091)\end{array}$ & $\begin{array}{r}0.30^{*} \\
(0.15)\end{array}$ & $\begin{array}{l}-0.052 \\
(0.035)\end{array}$ & $\begin{array}{l}-0.061 \\
(0.042)\end{array}$ & $\begin{array}{l}-0.15^{* *} \\
(0.071)\end{array}$ & $\begin{array}{l}-0.22^{* *} \\
(0.097)\end{array}$ \\
\hline Drop control markets within & $5 \mathrm{~km}$ & $10 \mathrm{~km}$ & $5 \mathrm{~km}$ & $10 \mathrm{~km}$ & $5 \mathrm{~km}$ & $10 \mathrm{~km}$ & $5 \mathrm{~km}$ & $10 \mathrm{~km}$ \\
\hline Wild bootstrap p-value (post $\cdot$ entry) & 0.14 & 0.07 & 0.00 & 0.01 & 0.17 & 0.21 & 0.05 & 0.06 \\
\hline Observations & 629 & 472 & 202 & 149 & 629 & 472 & 202 & 149 \\
\hline$R^{2}$ & 0.06 & 0.05 & 0.26 & 0.28 & 0.13 & 0.13 & 0.24 & 0.20 \\
\hline
\end{tabular}

Note: Market-clustered standard errors appear in parentheses. Odd columns omit 4 control markets that are within 5 kilometers by road of the nearest treatment market. Even columns omit 8 control markets that are within 10 kilometers by road of the nearest treatment market. ${ }^{*} p<0.1$, ** $p<0.05,{ }^{* * *} p<0.01$. 
Appendix Table 6: The Impact of Chain Entry on Consumer Preferences

\begin{tabular}{|c|c|c|c|c|c|c|}
\hline & \multicolumn{6}{|c|}{ Perceived Importance of: } \\
\hline & \multicolumn{2}{|c|}{ Drug Quality } & \multicolumn{2}{|c|}{ Store Convenience } & \multicolumn{2}{|c|}{ Store Familiarity } \\
\hline & $(1)$ & $(2)$ & $(3)$ & (4) & $(5)$ & $(6)$ \\
\hline Round $2 \cdot$ entry market & $\begin{array}{c}0.28^{* * *} \\
(0.077)\end{array}$ & $\begin{array}{c}0.28^{* * *} \\
(0.079)\end{array}$ & $\begin{array}{c}0.045 \\
(0.063)\end{array}$ & $\begin{array}{c}0.076 \\
(0.053)\end{array}$ & $\begin{array}{l}-0.014 \\
(0.069)\end{array}$ & $\begin{array}{c}0.006 \\
(0.092)\end{array}$ \\
\hline Round $3 \cdot$ entry market & $\begin{array}{c}0.28^{* * *} \\
(0.074)\end{array}$ & $\begin{array}{c}0.30^{* * *} \\
(0.073)\end{array}$ & $\begin{array}{c}-0.003 \\
(0.014)\end{array}$ & $\begin{array}{c}0.019 \\
(0.050)\end{array}$ & $\begin{array}{c}-0.13^{* *} \\
(0.047)\end{array}$ & $\begin{array}{c}-0.11 \\
(0.071)\end{array}$ \\
\hline Market demo and health controls & - & Yes & - & Yes & - & Yes \\
\hline \multicolumn{7}{|l|}{ Wild bootstrap p-value: } \\
\hline$\overline{\text { Round } 2 \cdot \text { entry }}$ & 0.00 & 0.00 & 0.51 & 0.26 & 0.84 & 0.95 \\
\hline Round $3 \cdot$ entry & 0.00 & 0.00 & 0.87 & 0.74 & 0.01 & 0.20 \\
\hline \multicolumn{7}{|l|}{ Proportional selection $\delta$ : } \\
\hline Round $2 \cdot$ entry & - & -2.94 & - & -0.01 & - & -0.06 \\
\hline Round $3 \cdot$ entry & - & -8.24 & - & -0.34 & - & 1.13 \\
\hline Observations & 2575 & 2575 & 2632 & 2632 & 2631 & 2631 \\
\hline$R^{2}$ & 0.08 & 0.10 & 0.09 & 0.12 & 0.23 & 0.24 \\
\hline
\end{tabular}

Note: Market-clustered standard errors appear in parentheses. All regressions include market fixed effects. ${ }^{*} p<0.1,{ }^{* *} p<0.05$, *** $p<0.01$. 


\section{References}

Allen, Franklin, "Reputation and Product Quality," Rand Journal of Economics, Autumn 1984, $15(3), 311-327$.

Altonji, Joseph, Todd Elder, and Christopher Taber, "Selection on Observed and Unobserved Variables: Assessing the Effectiveness of Catholic Schools," Journal of Political Economy, 2005, 113 (1), 151-184.

Baird, Sarah, Joan Hamory Hicks, Michael Kremer, and Edward Miguel, "Worms at Work: Long-run Impacts of Child Health Gains," March 2012. Unpublished manuscript.

Basker, Emek, "Selling a Cheaper Mousetrap: Wal-Mart's Effect on Retail Prices," Journal of Urban Economics, 2005, 58, 203-229.

_ _ and Michael Noel, "The Evolving Food Chain: Competitive Effects of Walmart's Entry into the Supermarket Industry," Journal of Economics and Management Strategy, Winter 2009, 18 (4), 977-1009.

Bate, Roger and Kathryn Boateng, "Bad Medicine in the Market," American Enterprise Institute Health Policy Outlook, June 2007, 8.

, Ginger Zhe Jin, and Aparna Mathur, "Does Price Reveal Poor-Quality Drugs? Evidence from 17 Countries," Journal of Health Economics, 2011, 30, 1150-1163.

__ _ _ a , and _ , "In Whom We Trust: the Role of Certification Agencies in Online Drug Markets," March 2012. NBER Working Paper 17955.

Bennett, Daniel, Che-Lun Hung, and Tsai-Ling Lauderdale, "Health Care Competition and Antibiotic Use in Taiwan," Journal of Industrial Economics, 2015. Forthcoming.

Bennett, Victor Manuel, Lamar Pierce, Jason A. Snyder, and Michael W. Toffel, "Customer-Driven Misconduct: How Competition Corrupts Business Practices," Management Science, 2013, 59 (8), 1725-1742.

Berry, Steven and Joel Waldfogel, "Product Quality and Market Size," Journal of Industrial Economics, March 2010, 58 (1), 1-31.

Bjorkman-Nyqvist, Martina, Jakob Svensson, and David Yanagizawa-Drott, "Can Good Products Drive Out Bad? Evidence from Local Markets for (Fake?) Antimalarial Medicine in Uganda," August 2012. Unpublished manuscript.

Cameron, A. Colin, Jonah Gelbach, and Douglas Miller, "Bootstrap-based Improvements for Inference with Clustered Standard Errors," Review of Economics and Statistics, August 2008, 90 (3), 414-427. 
Cockburn, Robert, Paul Newton, E. Kyeremetang Agyarko, Dora Akunyili, and Nicholas White, "The Global Threat of Counterfeit Drugs: Why Industry and Governments Must Communicate the Dangers," PLoS Medicine, April 2005, 2 (4), 302-308.

Corporate Catalyst India, "A Brief Report on India's Pharmaceutical Industry," March 2012.

Das, Prashant, Vivek Sah, Divyanshu Sharma, Vinod Singh, and Louis Galuppo, "Real Estate Development Process in India," Journal of Real Estate Literature, 2013, 21 (2), 271-292.

Domberger, Simon and Avrom Sherr, "The Impact of Competition on Pricing and Quality of Legal Services," International Review of Law and Economics, 1989, 9, 4156 .

Donald, Stephen and Kevin Lang, "Inference with Difference-in-Differences and Other Panel Data," Review of Economics and Statistics, may 2007, 89 (2), 221-233.

Dondorp, AM, PN Newton, M Mayxay, W Van Damme, FM Smithuis, S Yeung, A Petit, AJ Lynam, A Johnson, TT Hien, R McGready, Farrar JJ, S Looareesuwan, NPJ Day, MD Green, and NJ White, "Fake antimalarials in Southeast Asia are a major impediment to malaria control: multinational cross-sectional survey on the prevalence of fake antimalarials," Tropical Medicine and International Health, December 2004, 9 (12), 1241-1246.

Dorfman, Robert and Peter Steiner, "Optimal Advertising and Optimal Quality," American Economic Review, December 1954, 44, 826-36.

Dranove, David and Mark A. Satterthwaite, "The Industrial Organization of Health Care Markets," in A. J. Culyer and J. P. Newhouse, eds., Handbook of Health Economics, Volume 1, 2000, pp. 1093-1139.

and Mark Satterthwaite, "Monopolistic Competition When Price and Quality are Imperfectly Observable," RAND Journal of Economics, Winter 1992, 23 (4), 518-534.

Drusano, George, "Antimicrobial Pharmacodynamics: Critical Interactions of 'Bug and Drug'," Nature Reviews Microbiology, April 2004, 2, 289-300.

Gaurdiano, Maria Cristina, Anna Di Maggio, Emilia Cocchieri, Eleonora Antoniella, Paola Bertocchi, Stefano Alimonti, and Luisa Valvo, "Medicines informal market in Congo, Burundi and Angola: counterfeit and sub-standard antimalarials," Malaria Journal, February 2007, 6 (22).

Hotelling, H., "Stablity in Competition," Economic Journal, 1929, 39, 41-57.

Jia, Panle, "What Happens When Walmart Comes to Town: an Empirical Analysis of the Discount Retailing Industry," Econometrica, November 2008, 76 (6), 1263-1316. 
Jin, Ginger and Phillip Leslie, "Reputational Incentives and Restaurant Hygiene," American Economic Journal: Microeconomics, 2009, 1 (1), 237-267.

Kamat, Vinay and Mark Nichter, "Pharmacies, Self-Medication, and Pharmaceutical Marketing in Bombay, India," Social Science and Medicine, 1998, 47 (6), 779-794.

Kashmir Times, "Spurious Drugs' Menace," December 172009.

Kiron, S, Arun Shirwaikar, and Saritha M, "Influence of Storage Conditions on the Potency of Amoxicillin Dispersible Tablets Stores in Hospital and Community Pharmacies in Different Regions of Kerala," Asian Journal of Pharmaceutical and Clinical Research, 2011, 4 (3), 101-102.

Krauth, Brian, "Bounding a Linear Causal Effect Using Relative Correlation Restrictions," August 2011. Unpublished manuscript.

Kreps, David and Jose Scheinkman, "Quantity Precommitment and Bertrand Competition Yield Cournot Outcomes," The Bell Journal of Economics, 1983, 14, 326-337.

Landes, William and Richard Posner, The Economic Structure of Tort Law, Harvard University Press, 1987.

Mahesh, Koride, "Drug Analysis Reports Come After Expiry Date!," The Times of India, January 262010.

Matsa, David, "Competition and Product Quality in the Supermarket Industry," Quarterly Journal of Economics, August 2011, 126 (3), 1539-91.

Mazzeo, Matthew, "Competition and Service Quality in the Airline Industry," Review of Industrial Organization, 2003, 22, 275-296.

Miguel, Edward and Michael Kremer, "Worms: Identifying Impacts on Education and Health in the Presence of Treatment Externalities," Econometrica, January 2004, 72 (1), 159-217.

Milgrom, Paul and John Roberts, "Price and Advertising Signals of Product Quality," Journal of Political Economy, 1986, 94 (4), 796-821.

Mubengayi, C. Kalonji, Y. Ramli, M. El Karbane, M. Azougagh, Y. Cherrah, and E. M. Essassi, "Study of the Accelerated Stability of Amoxicillin Made in DR Congo," Journal of Chemical and Pharmaceutical Research, 2013, 5 (4), 126-132.

Nelson, Philip, "Information and Consumer Behavior," Journal of Political Economy, March-April 1970, 78 (2), 311-29. , "Advertising as Information," Journal of Political Economy, 1974, 82 (4), 729-54. 
Newton, PN, FM Fernandez, A Plancon, DC Mildenhall, MD Green, Z Li, EM Christophel, S Phanouvong, S Howells, E McIntosh, P Laurin, N Blum, CY Hampton, K Faure, L Nyadong, CWR Soong, B Santoso, Z Wang, J Newton, and K Palmer, "A Collaborative Epidemiological Investigation into the Criminal Fake Artesunate Trade in South East Asia," PLoS Medicine, February 2008, 5 (2), 209-219.

Oster, Emily, "Unobservable Selection and Coefficient Stability: Theory and Evidence," February 2014. Unpublished manuscript.

Peace, Nwokoye, Oyetunde Olubukola, and Akinleye Moshood, "Stability of Reconstituted Amoxicillin Clavulanate Potassium under Simulated In-Home Storage Conditions," Journal of Applied Pharmaceutical Science, 2012, 2 (1), 28-31.

Salop, Steven, "The Noisy Monopolist: Imperfect Information, Price Dispersion, and Price Discrimination," Review of Economic Studies, October 1977, 44 (3), 393-406.

_ _ and Joseph Stiglitz, "Bargains and Ripoffs: A Model of Monopolistically Competitive Price Dispersion," Review of Economic Studies, October 1977, 44 (3), 493-510.

Shaked, Avner and John Sutton, "Relaxing Price Competition Through Product Differentiation," Review of Economic Studies, January 1982, 49 (1), 3-13.

Sheth, Prafull, Brijesh Regal, Madhulika Kaushal, Kaustav Sen, and D. B. A. Narayana, "Extent of Spurious (Counterfeit) Medicines in India," Technical Report, SEARPharm Forum 2007.

Sow, PS, TSN Gueye, E Sy, L Toure, C Ba, and M Badiane, "Drugs in the Parallel Market for the Treatment of Urethral Discharge in Dakar: Epidemiological Investigation and Physicochemical Tests," International Journal of Infectious Diseases, 2002, 6 (2), $108-12$.

Spence, A. Michael, "Monopoly, Quality, and Regulation," Bell Journal of Economics, Autumn 1975, 6 (2), 417-29.

Spence, Michael, "Consumer Misperceptions, Product Failure, and Producer Liability," Review of Economic Studies, October 1977, 44 (3), 561-572.

Taylor, RB, O Shakoor, RH Behrens, M Everard, AS Low, J Wangboonskul, RG Reid, and JA Kolawole, "Pharmacopoeial Quality of Drugs Supplied by Nigerian Pharmacies," Lancet, June 16 2001, 357, 1933-36.

Tirole, Jean, The Theory of Industrial Organization, Massachusetts Institute of Technology, 1988.

Trefi, Saleh, Veronique Gilard, Myriam Malet-Martino, and Robert Martino, "Generic ciprofloxacin tablets contain the state amount of drug and different impurities profiles: A 19F, 1H and DOSY NMR Analysis," Journal of Pharmaceutical and Biomedical Analysis, 2007, 44, 743-754. 
Woodcock, J, "The Concept of Pharmaceutical Quality," American Pharmaceutical Review, 2004, 7 (6), 10-15.

Yu, Lawrence X., "Pharmaceutical Quality by Design: Product and Process Development, Understanding, and Control," Pharmaceutical Research, April 2008, 25 (4), 781-91. 